\title{
Insulators: many functions, many mechanisms
}

\author{
Adam G. West, ${ }^{1}$ Miklos Gaszner, ${ }^{1}$ and Gary Felsenfeld ${ }^{2}$ \\ Laboratory of Molecular Biology, National Institute of Diabetes and Digestive and Kidney Diseases, National Institutes \\ of Health, Bethesda, Maryland 20892-0540, USA
}

Eukaryotic genomes are organized into domains containing individual genes and gene clusters that have distinct patterns of expression both during development and in differentiated cells. These genomes contain regulatory elements such as enhancers that are able to activate target genes in cis over considerable distances. They may also contain extended regions of condensed chromatin capable of encroaching on adjacent domains to perturb gene expression. There are a number of ways in which individual domains could be maintained independent of their surroundings through the establishment of boundaries. These boundaries might be variable in position, and established through a balance between countervailing processes (such as condensation and decondensation of chromatin domains). Alternatively, specific DNA sequences and associated proteins might have the role of establishing fixed boundaries.

"Insulator" is the name given to a class of DNA sequence elements that possess a common ability to protect genes from inappropriate signals emanating from their surrounding environment. A useful distinction may be made between the two ways in which insulators protect an expressing gene from its surroundings. The first way is by blocking the action of a distal enhancer on a promoter (Geyer and Corces 1992; Kellum and Schedl 1992). Enhancer blocking only occurs if the insulator is situated between the enhancer and the promoter, not if it is placed elsewhere. Such activity can prevent an enhancer from activating expression of an adjacent gene from which it is blocked, while leaving it free to stimulate expression of genes located on its unblocked side (Fig. 1A). The second way in which insulators protect genes is by acting as "barriers" (Sun and Elgin 1999) that prevent the advance of nearby condensed chromatin that might otherwise silence expression. Some insulators are able to act both as enhancer blockers and barriers (Table 1). Others, particularly in yeast, serve primarily as barriers. In at least the example of the chicken $\beta$-globin HS4 element, the two activities can occur together but are separable (discussed below).

\footnotetext{
${ }^{1}$ These authors contributed equally to this review.

${ }^{2}$ Corresponding author.

E-MAIL gary.felsenfeld@nih.gov; FAX (301) 496-0201.

Article and publication are at http://www.genesdev.org/cgi/doi/10.1101/ gad.954702.
}

Because the phenotype associated with insulator activity can be generated in any number of ways that interfere with enhancer action or chromatin condensation, there is every reason to expect that unique mechanisms should be involved. Indeed, attempts to explain all the data from all known insulators with a single model will probably be unsuccessful. Despite this cautionary note, a few themes are beginning to appear repeatedly in papers dealing with insulators. Some studies that deal primarily with enhancer blocking focus on the involvement of insulators in protein-protein interactions that may interfere with the activity of complexes mediating normal enhancer-promoter communication. At least one insulator appears to mediate chromatin loop formation, raising the possibility that this somehow reduces the frequency of interaction between elements separated by the insulator. Other results, mainly concerned with the role of insulators in protection against the formation and propagation of condensed chromatin, point toward a role of some insulators in targeting histone modification. The assays for both enhancer blocking and barrier activity involve constructs that show these properties, but do not necessarily reveal the function of an insulator at its normal chromosomal location. An important consequence of recent results is that we are now able to devise testable models to assess the role of insulators in their natural environments.

\section{Enhancer-blocking elements}

The discovery that eukaryotic transcriptional activators are able to function over long distances in an orientationindependent manner posed several new questions. One of these was how the long-range activation potential of eukaryotic enhancers could be restricted to the relevant target promoter. Despite recent results showing that some enhancers are specific for certain promoters (Butler and Kadonaga 2001; Smale 2001), transgene experiments using heterologous enhancer-promoter combinations suggest that this specificity is rather limited and would not be sufficient to account for the restricted range of enhancer action. Instead, it was proposed that eukaryotic chromatin is organized into functionally independent domains to prevent illegitimate enhancer-promoter communication. These models predicted the existence 


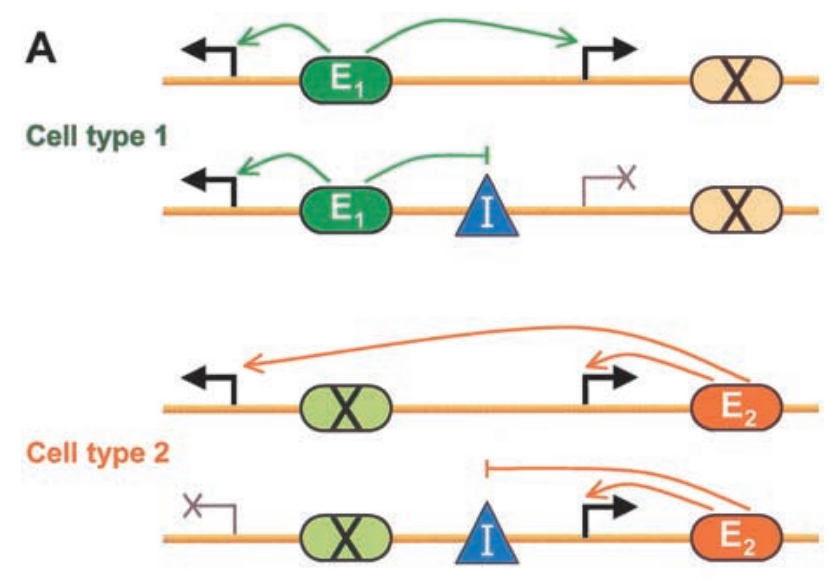

B

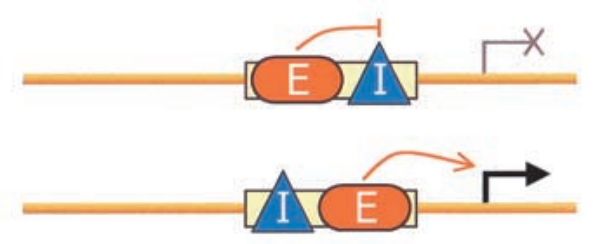

\section{C}
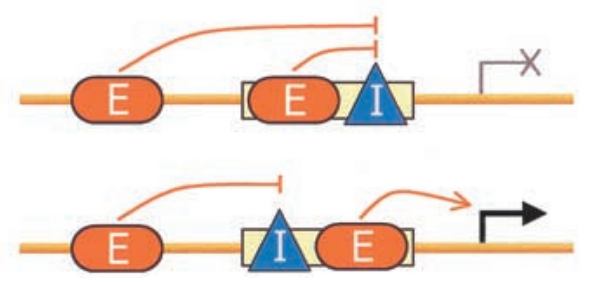

Figure 1. Characterizing enhancer-blocking elements. $(A)$ Transgenic constructs containing two promoters that can be driven by enhancers that function in cell types 1 or 2 (green and red, respectively). The insulator element with enhancer-blocking properties (shown as a blue triangle) only blocks enhancerpromoter communication when positioned between an active enhancer and promoter. Enhancer blocking occurs without hindering the ability of the enhancer or promoter to function elsewhere. (B) Compound elements (yellow box) of closely spaced enhancers (red) and enhancer blockers (blue) will appear polar in nature in transgenic assays. The upper two constructs show that without further enhancement the compound element will appear as a polar enhancer; only one orientation enhances transcription. $(C)$ When placed between an existing enhancer and promoter, the compound element will appear as a polar enhancer blocker; only one orientation blocks enhancement.

of specialized boundary complexes that could block an enhancer from activating a promoter located in the adjacent domain.

\section{Assays for enhancer-blocking activity}

Considerable effort has been directed toward the identification and characterization of enhancer-blocking elements. Two experimental approaches were developed originally in Drosophila melanogaster for this purpose. The position effect assay takes advantage of one form of chromosomal position effect: the activation of transgenic promoters by chromosomal enhancers located in the vicinity of the transgene's site of insertion (Kellum and Schedl 1991). As the chromosomal enhancers interacting with the transgene vary from one insertion site to the next, independently generated lines often have different expression patterns. Enhancer-blocking activity can therefore be assessed by testing an element's ability to protect a transgene against the influence of chromosomal enhancers surrounding it. Effective protection ensures that independently generated transgene lines express the reporter gene uniformly at the level determined by the construct itself. It is important that the enhancer blocker be present both at the $5^{\prime}$ and $3^{\prime}$ ends of the transgene because position effect could originate from either direction.

We note here that transgenes might also be subject to a different form of chromosomal position effect, variegated silencing by adjacent condensed chromatin. Protection against this type of position effect is discussed below in the section on elements that have barrier activity. What form of chromosomal position effect a randomly inserted transgene is likely to experience is largely dependent on the experimental organism used. In Drosophila, where most early insulator studies were carried out, there are few extended regions of condensed chromatin outside centromeres and telomeres (discussed in Sun et al. 2000). Additionally, P-element-mediated germ-line transformation preferentially targets transgenes to open chromatin regions (Bownes 1990). The behavior of transgenes in Drosophila therefore predominantly reflects the proximity of enhancers, a fact that is exploited in enhancer trap screens $\left(\mathrm{O}^{\prime}\right.$ Kane and Gehring 1987). As discussed below, the situation is quite different in vertebrates.

A second assay for enhancer blocking was developed to determine an element's ability to interfere with communication between a particular enhancer and promoter (Geyer and Corces 1992; Kellum and Schedl 1992). In this assay, the experimental constructs contain all the necessary components: enhancer, promoter, and blocking element (Fig. 1A). An element with enhancer-blocking activity is able to interfere with enhancer-promoter communication when inserted between the enhancer and the promoter. The same element has little or no effect on transcriptional activation when present in a position flanking the enhancer-promoter pair. The second characteristic distinguishes enhancer-blocking elements from silencers that are expected to reduce expression of the reporter gene from both positions.

\section{Proteins with enhancer-blocking ability}

A wide variety of enhancer-blocking elements have been identified. Most of them are found in Drosophila, but increasing numbers are being identified in vertebrates (Table 1). Detailed understanding of enhancer-blocking complexes requires the identification and characterization of their protein components. A combination of genetic, molecular, and biochemical approaches led to the 
identification of four DNA-binding proteins that are sufficient to block enhancer-promoter communication. Three of them, su(Hw) (Parkhurst et al. 1988), BEAF (Zhao et al. 1995), and Zw5 (Gaszner et al. 1999), were found in D. melanogaster. Interestingly, there is no great similarity among either the DNA-binding sites of these proteins or the proteins themselves, which suggests that they may use different molecular interactions for enhancer blocking. CTCF, which is also unrelated in sequence and interacts with distinct binding sites, provides the first example of a vertebrate enhancer-blocking protein (Bell et al. 1999). So far, all of the characterized enhancer-blocking elements identified in vertebrates bind CTCF. A fifth factor, the GAGA protein, has been implicated in the enhancer-blocking activity of the Drosophila eve promoter region (Ohtsuki and Levine 1998). However, GAGA alone is not sufficient to block enhancer-promoter communication.

Probably the most extensively studied enhancerblocking system is the protein su(Hw), and the array of binding sites within the gypsy retrotransposon with which it interacts (Spana et al. 1988). Of the protein domains comprising su(Hw), 9 out of 12 Zinc fingers and the C-terminal leucine zipper, but not the $\mathrm{N}$ - and $\mathrm{C}$ terminal acidic regions, are required for enhancer blocking (Harrison et al. 1993; Kim et al. 1996). Molecular analysis of gypsy-induced mutations suggested that the retrotransposon had position-dependent enhancer-blocking activity. This was subsequently shown in transgenebased assays, which also confirmed that the activity is mediated by an 400 -bp subfragment consisting of 12 directly repeated copies of a short sequence motif capable of binding su(Hw) (Geyer and Corces 1992). A cofactor, $\bmod (\operatorname{mdg} 4)$, binds to $\mathrm{su}(\mathrm{Hw})$ and is essential for its enhancer-blocking activity (see below; Gerasimova et al. 1995). The gypsy element provides a clear example of an insulator that shows enhancer-blocking activity in situ, beyond the confines of specially designed constructs.

\section{Polarity of enhancer blockers}

Some blocking elements appear to show polarity, that is, their function is orientation-dependent. For example, the enhancer-blocking elements in the imprinted control region (ICR) within the imprinted mouse Igf2/H19 locus function better as insulators when placed in one orientation than they do when reversed (Bell and Felsenfeld 2000; Hark et al. 2000). The enhancer-blocking activity arises from CTCF sites present within the ICR, but these elements are much larger than the CTCF-binding sites and may contain other regulatory sequences. Such combinations have been reported, for example, near 5'HS5 of the human $\beta$-globin locus, where early studies at first failed to detect enhancer-blocking activity because of the proximity of an enhancer that masked it (Chung et al. 1993). Another very clear example can be found upstream of the human $а р о B$ locus and is mentioned below. Compound elements containing both enhancerblocking and enhancer activities would be expected to show polar behavior (Fig. 1B; Barges et al. 2000). When the combined insulator-enhancer element is oriented with the insulator closer to the promoter, that enhancer as well as others more distal will be blocked. When the combination element is reversed, the distal enhancers are still blocked, but the insulator-associated enhancer is now free to activate the reporter.

Recent studies (Kmita et al. 2000) of the mouse HoxD complex have revealed the presence of a polar silencer, located between Hoxd12 and Hoxd13 (Fig. 2). Expression of genes in this region is driven in appropriate tissues by the digit enhancer, the hernia enhancer, or both. These are located at either end of the cluster. The polar silencer blocks one of the enhancers from activating genes beyond it. Which enhancer is blocked depends on the orientation of the silencer. Although this is difficult to reconcile with insulator function, we suggest that the polar behavior could be explained if an enhancer blocker were adjacent to an element that overcame the insulation activity under the control of the enhancer that was not blocked. In a given orientation, only the unblocked enhancer would be able to do this, giving rise to the observed behavior (see Fig. 2 legend).

\section{How do enhancer blockers work?}

The main difficulty in explaining enhancer blocking is to account for the asymmetry of the activity (Fig. 1). In turn, that asymmetric behavior (which we call position dependence) places restrictions on possible enhancer mechanisms. Because of the intimate connection between models for enhancer activity and enhancer blocking, we will discuss them together.

Unfortunately, we have only approximate and rather conflicting notions of how enhancers actually work. Our most direct knowledge of how enhancers might activate transcription come from studies of yeast upstream activating sequences (UAS; Farrell et al. 1996), where the evidence is strong that UAS-bound proteins interact with components of the transcription complex to raise the probability that it will find (have a stabilized interaction with) the promoter. The proposed mechanism for enhancer activity has been expanded to include the targeting of chromatin-modifying enzymes (e.g., HATs, remodeling complexes) to the promoter region, thus making the promoter more accessible to the transcriptional machinery. Although the underlying molecular interactions are conserved, the situation in higher eukaryotes is complicated by the fact that enhancers tend to be much farther from the promoter than in yeast, making chance enhancer-promoter encounters less likely.

Several mechanisms have been invoked to explain enhancer function at a distance. Many of them envision a processive (or "tracking") action that relays the enhancement signal/activity from enhancer to promoter along the chromatin fiber. A nucleoprotein complex that lies between the enhancer and the promoter and is able to disrupt this process will act as an enhancer blocker.

Some evidence from studies of the human $\beta$-globin locus supports the view that RNA polymerase II (Pol II) 
Table 1. Insulator elements and their proposed in situ function

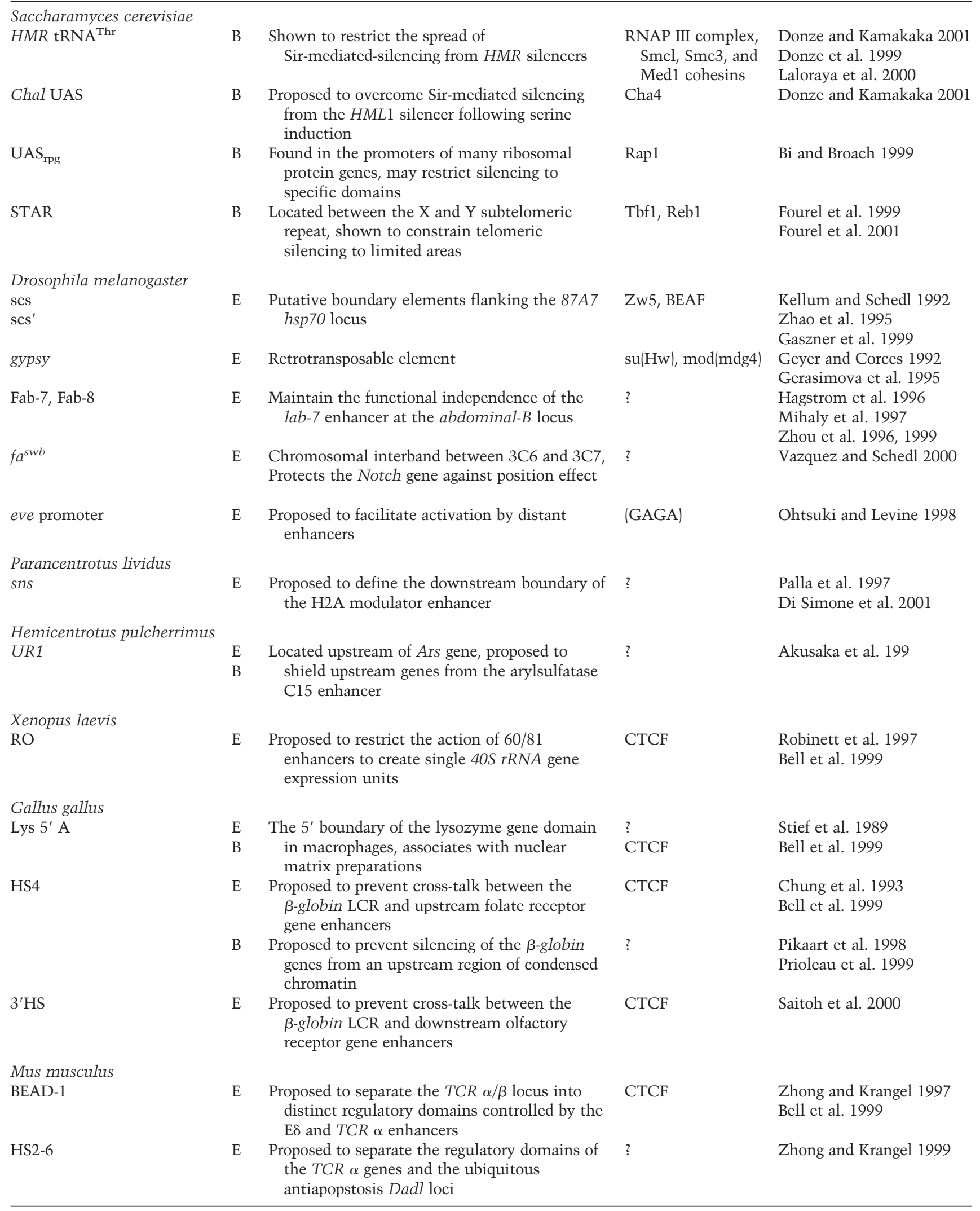


Table 1. (Continued)

\begin{tabular}{|c|c|c|c|c|}
\hline $\mathrm{DMD} / \mathrm{ICR}$ & $\mathrm{E}$ & $\begin{array}{l}\text { Located between the reciprocally imprinted Igf2 } \\
\text { and } H 19 \text { genes, shown to block the access of } \\
\text { Igf2 to downstream endodermal enhancers on } \\
\text { the maternally inherited allele }\end{array}$ & $\begin{array}{l}\text { CTCF (sensitive } \\
\text { to CpG methylation) }\end{array}$ & $\begin{array}{l}\text { Bell and Felsenfeld } 2000 \\
\text { Hark et al. } 2000 \\
\text { Kanduri et al. } 2000\end{array}$ \\
\hline \multicolumn{5}{|c|}{ Homo sapiens } \\
\hline $5^{\prime} \mathrm{HS} 5$ & $\mathrm{E}$ & $\begin{array}{l}\text { Located upstream of } \beta \text { globin locus control } \\
\text { region, may limit the action of the LCR to } \\
\text { the downstream globin genes }\end{array}$ & $?$ & $\begin{array}{l}\mathrm{Li} \text { and Stamatoyannopoulos 1994; } \\
\text { Yu et al. } 1994\end{array}$ \\
\hline $\mathrm{DMD} / \mathrm{ICR}$ & $\mathrm{E}$ & (See mouse DMD/ICR above) & & \\
\hline $\begin{array}{l}\text { apoB } \\
(-57 \mathrm{~kb})\end{array}$ & $\mathrm{E}$ & $\begin{array}{l}\text { Proposed to form the } 5^{\prime} \text { boundary of the } \\
\text { apolipoprotein } 8 \text { chromatin domain in } \\
\text { intestinal tissues }\end{array}$ & $\begin{array}{l}\text { CTCF } \\
?\end{array}$ & Antes et al. 2001 \\
\hline $\begin{array}{l}\text { apoB } \\
(+43 \mathrm{~kb})\end{array}$ & $\mathrm{B}$ & $\begin{array}{l}\text { Proposed to form the } 3^{\prime} \text { boundary of the } \\
\text { apolipoprotein B chromatin domain }\end{array}$ & $?$ & Namciu et al. 1998 \\
\hline$D M 1$ & $\mathrm{E}$ & $\begin{array}{l}\text { Located between the DMPK and SIX5 genes, } \\
\text { proposed to block access of the DMPK gene } \\
\text { to the SIX } 5 \text { enhancer }\end{array}$ & $\begin{array}{l}\text { CTCF (sensitive to } \\
\text { CpG methylation) }\end{array}$ & Filippova et al. 2001 \\
\hline
\end{tabular}

Observed properties are listed where $\mathrm{E}$ and $\mathrm{B}$ refer to enhancer blocking and barrier activities, respectively. We note that barrier activities in Drosophila may largely arise from enhancer blocking (see text).

could carry such a signal from upstream regulatory elements toward the promoter. Pol II-dependent transcripts have been detected more than $10 \mathrm{~kb}$ upstream of the $\beta$-globin genes, within the locus control region, as well as further downstream (Tuan et al. 1992; Ashe et al. 1997; Gribnau et al. 2000). Transcription occurs only in the direction of the genes. Some transcription begins within the gene cluster, under the control of a regulatory element that is important for high-level transcription of $\delta$ - and $\beta$-globin. It has been suggested that the transcription process perturbs chromatin structure between the upstream LCR elements and the promoters, helping to activate the genes. Perturbation could involve acetylation of the histones by enzymes associated with the advancing polymerase (Wittschieben et al. 1999). Alternatively, the transcription process might simply direct delivery of the polymerase to the promoters (Tuan et al. 1992). In either case it is easy to see how a nucleoprotein complex could interfere with the intergenic transcription and thus block the upstream enhancer from activating its target promoter.

Instead of sending a signal from afar, a distant enhancer might be brought close to the promoter by mechanisms that compact the intervening chromatin or otherwise reduce the distance between them. Particular attention has focused on the Drosophila Chip protein, which does not bind to DNA directly but can interact with a large number of transcription factors to facilitate their activity (Morcillo et al. 1996, 1997). Genetic evidence shows that su(Hw) becomes a more effective enhancer blocker when enhancer-promoter communication is weakened by mutations in Chip. Chip is a LIM domain binding (LDB) protein, with vertebrate homologs (Agulnick et al. 1996), that interacts with nuclear LIM proteins including LIM-homeodomain proteins but also with a variety of other homeodomain proteins, such as Bicoid (Bcd), that do not have LIM domains (Torigoi et al. 2000). Chip uses residues distinct from those involved in the LDB to interact with these proteins, as well as with $\mathrm{su}(\mathrm{Hw})$ and with itself. Chip can potentiate Bcd activity in Drosophila embryos and in yeast, and experiments in yeast show that Chip is effective in increasing activation in some situations where multiple Bcd sites are present. It is proposed that Chip dimers bind to and stabilize interactions between Bcd molecules, in turn increasing Bcd affinity for its sites on DNA. If the binding sites for these proteins are sparsely distributed between the enhancer and the promoter (Carr and Biggin 1999), the effect would be to decrease the spatial separation of enhancer and promoter, thus facilitating interaction between them. According to current models, recruitment of Chip by activator proteins clustered at the enhancer initiates the bidirectional spread of Chip-assisted homeodomain protein binding along the chromatin fiber that eventually brings the enhancer and the promoter together (Gause et al. 2001). It is an important feature of this model that it can account for how su(Hw) protein works to block enhancer action: Formation of the Chip$\mathrm{su}(\mathrm{Hw})$ complex could break the chain of interaction between Chip and homeodomain proteins, thus interfering with the process that brings the enhancer and the promoter together. Note that Chip-mediated condensation is assumed to be processive, starting only at the enhancer. Otherwise, it would be difficult to explain why a single su(Hw)/mod(mdg4) complex would have much overall effect on the separation between the enhancer and the promoter. This model is therefore related to other tracking models.

As we noted above, the simplest mechanism for bringing the promoter and the enhancer together is by loop formation, but this could present a problem when the distance between the promoter and the enhancer is large. The encounter between the enhancer and the promoter can then become rate-limiting in affecting transcription. This difficulty could be overcome by structures that shorten the effective distance between the enhancer and 

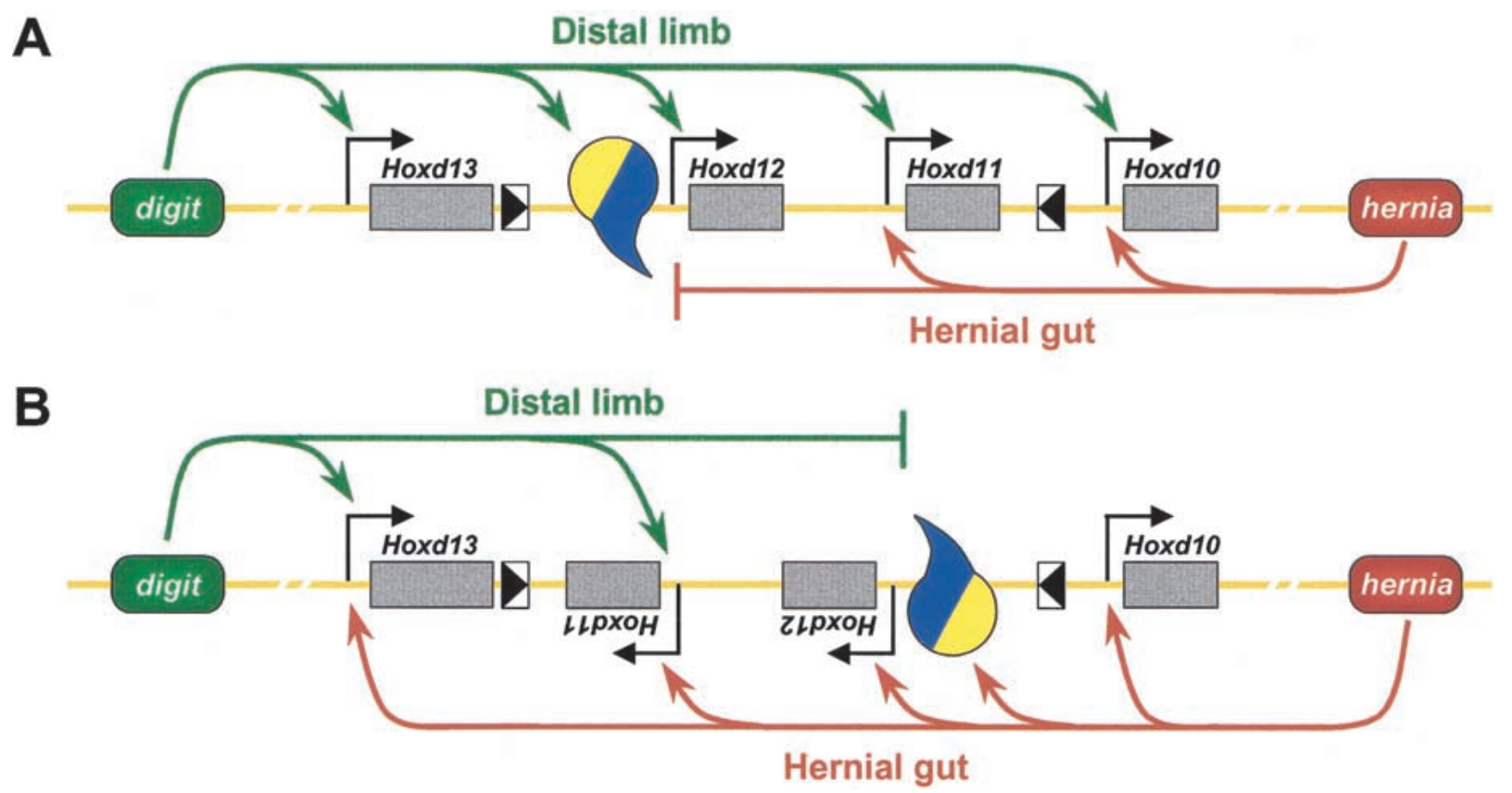

Figure 2. A polar element limits the range of enhancer action at the posterior HoxD gene cluster. The Hoxd10-13 genes (gray boxes) are regulated by the upstream digit (green) and downstream hernia (red) tissue-specific enhancers. (A) In a wild-type configuration, the hernia enhancer activates only the Hoxd10 and Hoxd11 genes in hernial gut tissues (red arrows), whereas the digit enhancer can activate all of the four genes in distal limb tissues (green arrows). (B) Inversion of the sequences between Hoxd13 and Hoxd10 following cre-mediated recombination (Cre sites shown as black triangles). In the inverted allele, action of the digit enhancer is restricted to the Hoxd13 and Hoxd11 genes, whereas the hernia enhancer can activate all four genes. Activity of the digit and hernia enhancers is restricted by a polar element located just upstream of the Hoxd12 promoter (indicated as a split comma symbol). We suggest that the polarity of this element could be explained by the close positioning of an enhancer-blocking element (blue) and an element that serves to switch off the enhancer blocker (yellow). The switch is assumed to be activated by either enhancer. The switch would not be activated if an enhancer blocker is positioned between the switch and the enhancer, giving rise to polarity of the combined elements. Assembly of the enhancer-blocking complex may inhibit the expression of the neighboring Hoxd12 promoter (adapted from Kmita et al. 2000).

the promoter, as Chip is proposed to do. Another possibility is that enhancer-targeting proteins bound to specific sites at the enhancer and the promoter interact to stabilize loop formation. To be effective, the interaction would have to be sufficiently stable so that the ratelimiting step was no longer a chance encounter. Given that assumption, it would be predicted that deletion of the promoter-proximal enhancer-targeting site (which does not in itself have promoter or enhancer activity) would diminish the distal enhancer's ability to activate transcription. However, this effect should be suppressed by a second, large deletion that moves the enhancer close to the promoter. A small DNA element with the above described characteristics has been found immediately upstream of the white promoter (Qian et al. 1992). Genetic studies of the $A b d-B$ gene also predict the existence of a promoter-proximal element that mediates activation by the distant iab enhancers (Sipos et al. 1998). The "decoy" model for enhancer blocking suggests that the insertion of a second targeting site upstream of the promoter should result in trapping the enhancer and keeping it from activating transcription (Geyer 1997). The decoy model is still a form of "tracking" model: It must include the assumption that the enhancer advances toward the promoter by some obligatory processive mecha- nism. This is necessary to explain the observed positiondependence that is characteristic of enhancer blocking. In the absence of a tracking process, the decoy element placed on the other side of the enhancer would work equally well, inconsistent with the position-dependence of enhancer blockers.

\section{Insulator bodies}

Detailed studies showed that distant chromosomal binding sites of su(Hw) are brought together by $\bmod (\operatorname{mdg} 4)$, the enhancer-blocking cofactor of su(Hw), into a small number of insulator bodies located at the nuclear periphery. This localization pattern is consistent with the idea that su(Hw) marks the base of topologically independent looped chromatin domains (Gerasimova and Corces 1998; Gerasimova et al. 2000; for review, see Bell et al. 2001). The importance of insulator body formation for gypsy-mediated enhancer blocking is emphasized by the observation that mutations disrupting the clusters also eliminate the element's blocking activity (Ghosh et al. 2001). These findings seem to support earlier proposals that $\mathrm{su}(\mathrm{Hw})$ complexes divide the chromosome into looped domains that are functionally isolated from one another, such that an enhancer in one loop could not 
productively interact with a promoter in another (for review, see Mongelard and Corces 2001). The insertion of a gypsy element between an enhancer and a promoter would in that case give rise to positional enhancer blocking.

It is important to keep in mind, however, that the formation of looped chromatin structures does not unambiguously determine a specific mechanism of enhancer blocking. Insulator bodies could also serve to interrupt a tracking mechanism. These clusters differ from individual gypsy arrays in several respects, any one of which could be important for enhancer blocking. Chromosomal su(Hw) complexes are likely to include and contribute to the insulator body several proteins that are not found at gypsy elements. Another important consequence of insulator body formation is that multiple distant chromatin fibers, perhaps containing promoters of other gene systems, are brought into close proximity (Fig. 3A). Such structures could interfere with tracking either by physically blocking the signal, or by diverting the signal to other branches of the array.

A new piece of the puzzle comes from two recently published studies on the enhancer-blocking effect of multiple, closely linked su(Hw)-binding arrays (Cai and Shen 2001; Muravyova et al. 2001). Both papers describe the analysis of a group of transgenes with more than one copy of the $\sim 400-b p$ su(Hw)-binding region from gypsy. The authors find that the introduction of a second or third copy of the su(Hw) array between the enhancer and its promoter inhibits enhancer blocking and may even strengthen activation by the enhancer. At the same time, two su(Hw) arrays flanking either the enhancer or the promoter are still capable of blocking enhancer-promoter communication. A potential explanation for the experimental results is that closely linked su(Hw) arrays may preferentially interact with each other (Fig. 3B). The consequence of such an interaction is twofold. First, it could prevent the targeting of the transgene to the insulator bodies thereby eliminating enhancer blocking. Second, if the multiple arrays lie between a promoter and an enhancer, it could bring them closer to each other and thus facilitate transcriptional activation. To account for all of the observations, one also has to propose that the presence of an active enhancer or promoter between two $\mathrm{su}(\mathrm{Hw})$ arrays inhibits their local interaction and allows them to associate with the insulator bodies (see details in Fig. 3B legend). If that is true, then tissue-specific factors determining the transcriptional status of the transgenes would also control their association with insulator bodies (Fig. 3B). The validity of these predictions can be tested readily by comparing the transgenes' subnuclear localization in various tissues.

These results might appear to exclude the possibility that the enhancer-blocking activity of su(Hw) involves tracking mechanisms or their variants, because according to these models, doubling the dose of su(Hw) arrays should increase rather than eliminate enhancer blocking (Mongelard and Corces 2001). However, pairwise interaction of adjacent gypsy arrays may prevent their transport to the insulator body. If this is the primary cause of the loss of blocking, we cannot eliminate any model, because as noted above we do not know the mechanism by which the insulator body plays its role in enhancer blocking.

\section{Role of enhancer-blocking elements in situ}

We pointed out above that the function of most identified enhancer-blocking elements at their original chromosomal location is not yet known. However, the recent advances in our understanding of enhancer blocking allow us to speculate on the potential roles of these elements. Most are proposed to function in gene regulation, but only in a few cases is there direct evidence for such a role. An example is the ICR element controlling the imprinted expression of $\mathrm{H} 19$ and Igf2 (Bell and Felsenfeld 2000; Hark et al. 2000; Kanduri et al. 2000). At the Igf2/ H19 locus in mouse, rat, and human, the Igf2 gene is expressed only from the paternally derived allele, and $H 19$ only from the maternal allele. The paternal allele is methylated in a region (the imprinted control region, or ICR) that lies between the two genes. Work in a number of laboratories (Thorvaldsen et al. 1998; Webber et al. 1998) suggested that the ICR contained an insulating element that might be responsible for preventing activation of Igf2 by downstream endodermal enhancers. This was subsequently confirmed by enhancer-blocking assays of the kind described above (Bell and Felsenfeld 2000; Hark et al. 2000; Kanduri et al. 2000; Holmgren et al. 2001). Binding sites were identified for the protein CTCF (see below) previously associated with enhancerblocking activity, and it was shown that DNA methylation at these sites abolished CTCF binding, and thus insulating activity. The evidence here strongly supports a major role for the insulator in blocking endodermal enhancer activation of Igf2 expression from the unmethylated allele. That function is abrogated by CpG methylation of the CTCF-binding sites, allowing Igf2 expression from the paternal allele.

Blocking elements can also play a vital role in maintaining the functional independence of an individual enhancer within a complex cis-regulatory region. The Fab-7 and Fab-8 blocking elements flanking the iab-7 enhancer of the D. melanogaster bithorax complex (BXC) were shown to function in such a capacity (Hagstrom et al. 1996; Zhou et al. 1996, 1999). Deletion of either Fab element interferes with the proper assembly of the iab-7 nucleoprotein complex and, in turn, leads to the misexpression of the $A b d-B$ homeotic gene (Galloni et al. 1993; Mihaly et al. 1997; Barges et al. 2000). Genetic studies support the argument that the role of the Fab elements is to shield $i a b-7$ against interference from the neighboring iab-5 and iab-6 regulatory units (for review, see Mihaly et al. 1998).

\section{Blocking elements may serve as structural components of chromatin}

Early biochemical experiments led to the proposal that eukaryotic chromatin is organized into a series of topo- 
West et al.

A

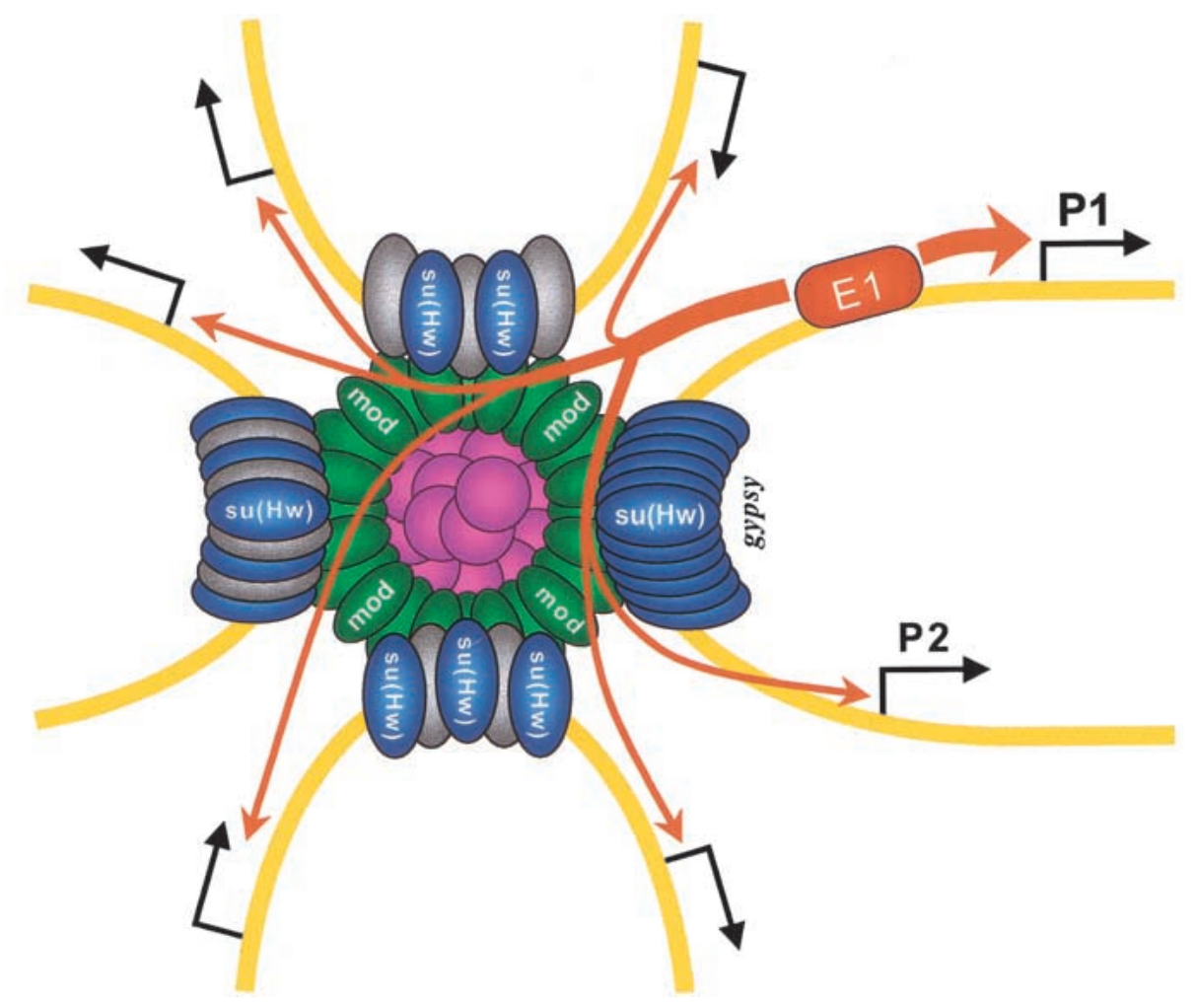

B
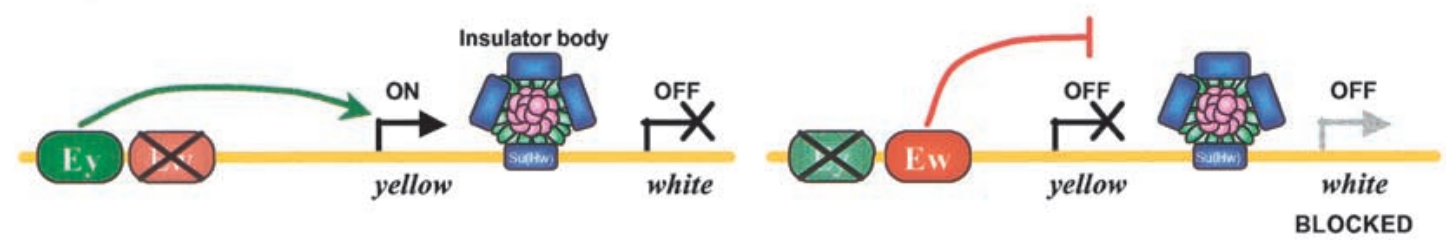

EyesYSW
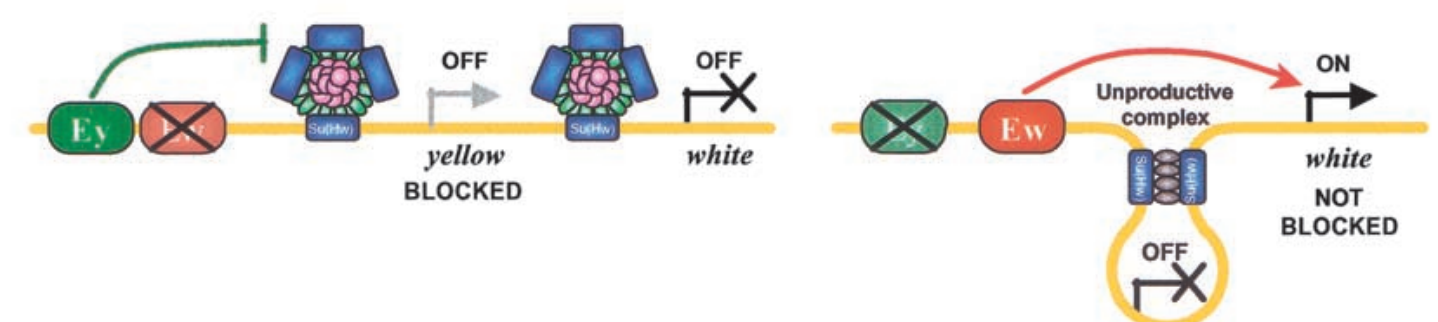

yellow
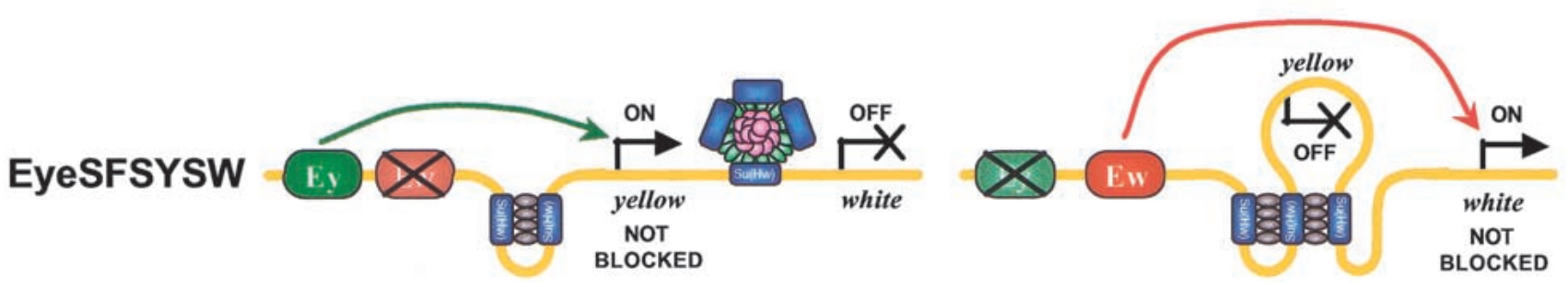

(Legend on facing page) 
logically independent structural units. Subsequent studies of gene regulation suggested that eukaryotic chromatin is divided into functionally independent domains. Inherent to both of these models is the existence of specialized boundary elements separating the individual structural or functional units. An important goal for chromatin research is to understand the relationship between the topological and gene regulatory boundaries, and therefore between the two kinds of organization. However, it should be kept in mind that even if the two coincide, this does not unambiguously determine a specific mechanism of enhancer blocking (see above).

The demonstration that all known putative boundaries of higher-order chromatin structures are also able to block enhancer-promoter interaction supports the idea that at least some of the identified enhancer-blocking elements serve as structural components of chromatin. Examples are provided by studies on $s c s, s c s^{\prime}$, and $f a^{s w b}$. scs and $s c s^{\prime}$ are the putative boundaries of the $87 A 7$ heat-shock domain of $D$. melanogaster (Udvardy et al. 1985). The two elements were shown to protect transgenes against chromosomal position effect and block enhancer-promoter interaction (Kellum and Schedl 1991, 1992). A more recent study of the $f a^{s w b}$ allele of the Notch gene implies a close connection between higherorder chromatin structures, transcriptional regulation, and enhancer blocking (Vazquez and Schedl 2000). $f a^{s w b}$ is a short deletion that removes an $\sim 880$-bp fragment upstream of the Notch transcription start site in D. melanogaster. The resulting misregulation of the Notch gene leads to the formation of rough eyes in homozygous mutant animals. A combination of genetic and molecular studies indicates that this defect is not due to the removal of specific upstream Notch regulatory elements. Instead, the results suggest that, as a consequence of the deletion, Notch becomes subject to chromosomal posi- tion effect interfering with its proper transcriptional regulation. The $f a^{s w b}$ deletion also leads to changes in higher-order chromatin structure. Cytological analysis of the mutant chromosome shows that the $f a^{s w b}$ deletion eliminates a chromosomal interband and thereby fuses the Notch-containing 3C7 band with its neighbor, 3C6 (Welshons and Keppy 1975). Taken together, the transcriptional and cytological phenotypes of $f a^{s w b}$ are consistent with the idea that the $\sim 800$-bp deletion removes a chromatin domain boundary element. The precise position of the putative boundary was recently mapped by determining the position of nuclease-hypersensitive sites in the corresponding chromatin fragment (Vazquez and Schedl 2000). More interestingly, the same study also showed that the $f a^{s w b}$ element is able to block enhancer-promoter communication.

\section{Blocking elements as transcriptional regulators}

Models (such as the decoy and Chip proposals) that posit direct interactions between enhancer-bound and insulator-bound proteins allow us to think of insulators as extensions of the normal apparatus of transcription. It has been suggested that when insulator sequences are located close to the promoter, as some are, they might serve in some cases to stabilize enhancer-promoter interaction (Ohtsuki and Levine 1998; Gause et al. 2001). When located away from the promoter, the same elements would compete for the enhancer and therefore interfere with transcriptional activation. A possible example is provided by the discovery that a 30-bp fragment located just upstream of the transcriptional initiation site of the even-skipped (eve; -30 to $-1 \mathrm{bp}$ ) gene possesses enhancer-blocking activity (Ohtsuki and Levine 1998). The blocking activity is separable from the TATA, Inr, and Dpe core elements. Targeted point mutations

Figure 3. (A) Diagrammatic representation of a su(Hw)/mod(mdg4) insulator body. Distant chromosomal binding regions of su(Hw)/ $\bmod (\mathrm{mdg} 4)$ (blue/green ovals) are brought together to form insulator bodies. Clustering is proposed to occur via multimerization of the mod(mdg4) BTB/POZ domain. The resulting complex comprises all the proteins and regulatory elements located in the vicinity of chromosomal su(Hw) binding sites. Chromosomal su(Hw) binding elements may interact with the insulator body via additional DNA-binding proteins (gray ovals). The gypsy insulator contains an array of $12 \mathrm{su}(\mathrm{Hw})$ sites. The close proximity of chromatin fibers (yellow) within the insulator body potentially enables promoters in trans (black arrows) to compete for the activity of the E1 enhancer (red) and thus dilute the enhancement signal (red arrows) relayed to the blocked promoter (P2). The insulator body has no effect on the ability of the E1 enhancer to activate P1. (B) Proposed explanation of the unanticipated behavior of su(Hw) insulators in transgenic experiments from Muravyova et al. 2001. The three constructions were assayed for the expression of the yellow and white genes in wing/body and eye tissues. (S) su(Hw); (F) spacer fragment; $(\mathrm{Y})$ yellow; (W) white. The white (EW, red) and yellow (Ey, wing and body, green) enhancers preferentially interact with the TATA-less white and TATA-containing yellow promoters, respectively. Arrays of 12 $\mathrm{su}(\mathrm{Hw})$ binding sites derived from the gypsy insulator are represented by blue boxes. The single su(Hw) array in EyeYSW blocks white expression in the eye and is expected to associate with the insulator body in both tissues. Two su(Hw) arrays flank the yellow gene in EyeSYSW. The two arrays are predicted to form intramolecular interactions in eye tissues and thus not be targeted to insulator bodies. Such interactions between the su(Hw) arrays loop out the inactive yellow gene and thus bring Ew closer to the white promoter. In wing and body cells, interaction between the active Ey enhancer and the yellow promoter interferes with local su(Hw) complex formation and targets the EyeSYSW arrays to the insulator body. Nuclear localization of EyeSYSW is predicted to be tissue-specific. Three su(Hw) arrays are present in EyeSFSYSW, two closely spaced arrays upstream of yellow and one downstream. Nuclear localization of EyeSFSYSW is also predicted to be tissue-specific. The two closely spaced su(Hw) arrays positioned between Ey and the yellow promoter should engage each other and not interfere with yellow activation. Transcription of yellow interferes with local complex formation by the downstream su(Hw) array and targets the EyeSFSYSW arrays to the insulator body in wing/body tissues. Inactivity of yellow enhancers in eye tissues permits the local interaction of all three su(Hw) arrays, causing EyeSFSYSW not to be targeted to insulator bodies and permitting white expression. Nuclear localization studies of these transgenes in wing/body and eye tissues can be used to test these models. 
disrupting a single GAGA-binding site located between TATA and the transcriptional initiation site of the eve promoter abolishes enhancer blocking but not transcription. The GAGA protein is necessary but not sufficient for the enhancer-blocking activity of the eve promoter; multiple GAGA motifs positioned further upstream in the promoter cannot compensate for the loss of a single element positioned between TATA and the initiation site.

As pointed out earlier, insulator body formation results in the clustering not only of the su(Hw) binding sites but also the regulatory elements linked to them. In this regard, it is important to mention that $\bmod (\operatorname{mdg} 4)$, the protein responsible for clustering su(Hw) into insulator bodies, is a member of the trithorax group of transcriptional activators. Mutations in several other trxG genes, whose protein products do not colocalize with $\mathrm{su}(\mathrm{Hw})$, also leads to changes in insulator body morphology. It may be that the high concentration of $\mathrm{su}(\mathrm{Hw})$ present in these bodies serves a normal cell function in providing a locus for attachment of Chip and other regulatory proteins, perhaps for the purpose of creating a subnuclear compartment permissive for high levels of transcription. In that view, the function of su(Hw) and its endogenous binding sites would be to target closely linked genes to a transcriptionally active nuclear compartment, perhaps a property taken advantage of by the gypsy retrotransposon for its own purposes (Smith and Corces 1995). This question can only be answered by identifying and characterizing some of the non-gypsy binding regions for $\mathrm{su}(\mathrm{Hw})$.

\section{Barrier elements protect against long-term repression}

The position effect assay (described above) has been used widely to identify vertebrate insulators with barrier activity (e.g., see Pikaart et al. 1998). Transgenes generated in vertebrate systems are often affected by both of the abovementioned forms of chromosomal position effects. The influence of transcriptional regulators positioned at the transgene's site of insertion leads to differences in expression pattern between independently generated lines. It is important to note that initially all cells of an individual line express the transgene at the same level. In long-term assays, the majority of the transgenes also become subject to epigenetic silencing by condensed chromatin. This form of position effect is nonuniform: at a given point in time, genetically identical cells will show different phenotypes, reflecting the variable extent to which the adjacent condensed chromatin has encroached on the transgene. In this regard, long-term silencing is very similar to the position effect variegation observed in Drosophila and yeast. Variegation in vertebrate cells is different in one important respect: there is no spontaneous reactivation of already silenced transgenes. This difference, however, is not likely to stem from divergent processes of silencing, but most likely can be accounted for by the fact that silenced states in vertebrate systems become fixed by CpG methylation, a mechanism not used by Drosophila or yeast.
A growing number of elements have been shown to protect against position effects in mammalian cells, many of which are summarized in Table 1. The HS4 insulator element from the upstream boundary of the chicken $\beta$-globin locus is the best characterized of these elements. Flanking transgene constructions with copies of the HS4 insulator has proved useful in the generation of many transgenic mouse (Wang et al. 1997; Potts et al. 2000; Boeda et al. 2001; Ciana et al. 2001), rabbit (TaboitDameron et al. 1999), and cell lines (Pikaart et al. 1998; Inoue et al. 1999; Emery et al. 2000; Rivella et al. 2000; Steinwaerder and Lieber 2000) with uniform transgene expression in all tissue types. HS4 is located at the boundary between the open chromatin of the active globin gene domain and an upstream region of condensed chromatin in erythroid cells (Prioleau et al. 1999). It has been proposed that the ability of HS4 to shield against chromosomal silencing in transgenic assays reflects a role at its endogenous location in preventing the incursion of the upstream repressive chromatin activities into the globin locus (Prioleau et al. 1999).

It is worth noting that the positioning of HS4 elements is critical for successful design of transgenic vectors. Like enhancer-blocking activity, the barrier activity of HS4 is position-dependent: it must be placed between the anticipated source of silencing and the transgenic elements to be shielded. For example, recent studies in which HS4 was used to shield transgenes in retroviral vectors underscore the need for insulators to be placed flanking the inserted transgenic elements so they can shield from both retroviral silencers and chromosomal position effect (Pannell and Ellis 2001). LCRs are dominant natural combinations of several powerful tissuespecific enhancers that are also capable of overcoming most position effects. We note that although LCRs can be useful for overcoming suppression of transgenic expression, their strict tissue-specificity and susceptibility to retroviral silencers makes them less useful for the shielding of transgenes (Q. Li et al. 1999; Ellis and Pannell 2001; Pannell and Ellis 2001). In addition, the lack of transcriptional enhancement by insulator elements themselves can facilitate the characterization of other transcriptional elements within a chromatin context (e.g., Boeda et al. 2001; Ciana et al. 2001).

\section{Barrier elements in yeast}

The best characterized barrier elements are found at the silent mating type loci and subtelomeric regions in the budding yeast Saccharomyces cerevisiae (for review, see Bi and Broach 2001). Haploid budding yeast carries transcriptionally silent copies of the mating-type specific $M A T \mathbf{a}$ and MAT $\alpha$ genes at the HMR and HML loci, respectively (Fig. 4A; for review, see Haber 1998). At both of the silent HM loci, the mating-type genes are flanked by silencer elements termed $E$ and $I$ that recruit the Sir $2 / 3 / 4$ protein complex that is responsible for repression. The silencing activity that results is restricted to the $H M$ loci by barrier elements that flank the $E$ and $I$ silencers. Movement or deletion of the barriers that flank $H M R$ 


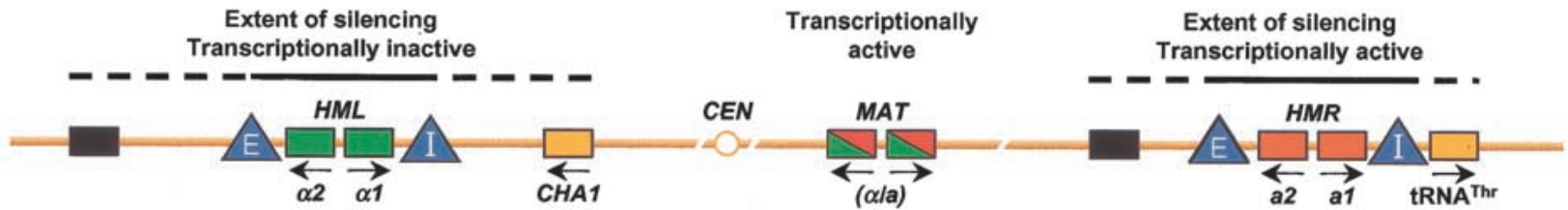

B

S. pombe

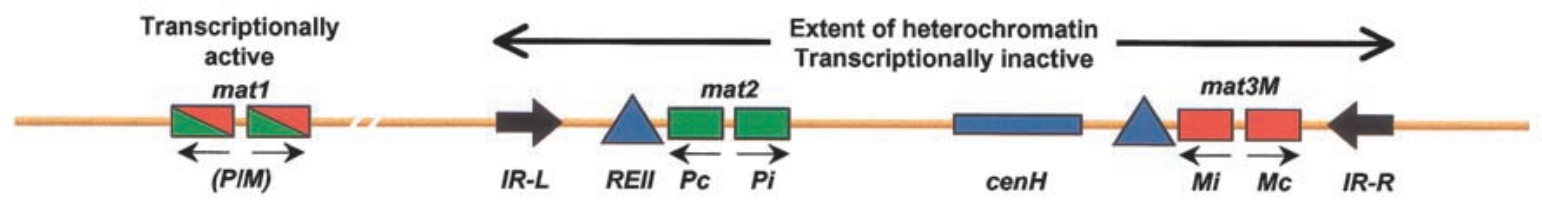

C

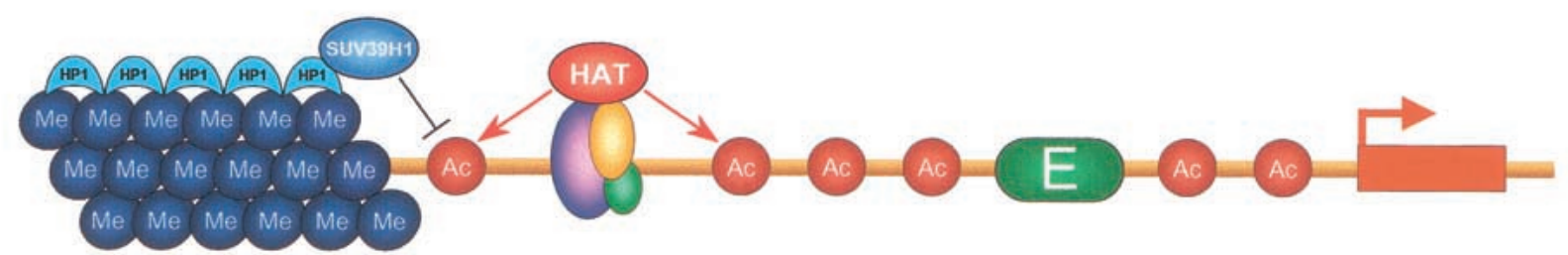

Condensed silent chromatin

Insulator

(barrier)

Open, active domain

Figure 4. (A) The mating-type loci on Chromosome III of Saccharomyces cerevisiae. The silent $\alpha$ - and a-type mating genes are located at the $H M L$ (green) and $H M R$ (red) loci, respectively. Active copies of either type are located at the MAT locus (red or green). Silencing at $H M L$ and $H M R$ is established by the $E$ and $I$ silencers that flank each locus (blue triangles). The downstream boundaries of silencing at $H M L$ and $H M R$ have been mapped to barrier elements at the CHA1 and $t R N A^{T h r}$ genes, respectively (orange, see text). (B) The mating-type loci on Chromosome II of Schizosaccharomyces pombe. The silent $P$ - and $M$-type mating genes are located at $m a t 2$ (green) and mat3 (red) loci, respectively. The active copy of either type is located at the mat1 locus (green or red). The mat2 and mat3 loci are silenced by the establishment of heterochromatin at cenH (blue) and additional silencers (blue triangles). The extent of heterochromatin has been mapped to inverted repeat sequences that flank the mat2/3 loci (black arrows, see text). (C) A model for the barrier activity of insulators (see text). A schematic diagram based on the example of the upstream boundary of the chicken $\beta$-globin locus. Insulator proteins constitutively recruit histone acetyltransferases that acetylate flanking nucleosomes (red spheres). Acetylation serves to inhibit histone modifications required for the propagation of transcriptionally silent condensed chromatin (packed blue spheres). HP1/SUV39H1 is shown as part of the spreading repressive protein complexes associated with Lys 9-methylated histone H3. Complexes of Sir proteins associated with deacetylated chromatin may be functionally analogous in budding yeast. Barriers act to terminate the chain of repressive chromatin by competing in the histone-modification process.

leads to expansion of the silent domain (Donze et al. 1999). The telomere-proximal barrier of $H M R$ has been mapped to a $t R N A^{T h r}$ gene (Donze and Kamakaka 2001). The activity of this barrier was found to require the transcriptional potential of this gene, as revealed by mutagenesis that disrupts the formation of a preinitiation complex.

Observations at the $H M L-I$ silencer have led to the suggestion that the boundaries of the silent HM locus domain may be determined by the polarity of the silencers themselves (Bi et al. 1999). However, it has been shown recently that silencing proteins associated with the silent domain spread beyond the silencers at both $H M L$ and $H M R$ (Fig. 4A; Lieb et al. 2001). The silencer proteins do not spread beyond the $H M R$ barrier elements described above. These studies collectively point to a stepped transition in chromatin structures at the boundaries of the $S$. cerevisiae HM locus. Silencer elements that are essentially polar in nature recruit silencer protein complexes that spread inward to establish a rigid silent domain. Heterochromatin barrier elements located either side of the mating-type loci are required to block the further spread of silencer proteins that leak out of the silent locus. It is worth noting that despite the presence of silencing proteins on chromatin between the $H M R-E$ silencer and the barrier, activity of a URA3 reporter gene is not as affected by silencing as it is if placed between the HMR-E and HMR-I silencers (Donze et al. 1999|. This suggests that the leaked silencer proteins are insufficient for full silencing activity.

The observations at the $S$. cerevisiae $H M$ locus are somewhat comparable with those at the silent matingtype loci of Schizosaccharomyces pombe. Haploid fission yeast carry transcriptionally silent copies of the mating-type-specific $M$ (minus) and $P$ (plus) genes at the mat2 and mat3 loci, respectively (Fig. 4B; for review, see Grewal 2000). Several cis elements at the mat2/3 loci serve to recruit trans-acting heterochromatic protein complexes that are responsible for repression. It has been proposed that the upstream boundary of the silent 
mat2/3 locus is established by the apparent polarity of the REII silencer. Deletion of REII leads to insufficient silencing of the mat2/3 locus, whereas inversion of $R E I I$ leads to spread of the silent domain (Ayoub et al. 2000). However, it has since been found that the proteins and histone modifications associated with silencing spread beyond the REII silencer (Noma et al. 2001). The 20-kb silent domain is particularly characterized by the presence of the Drosophila HP1 homolog Swi6 and histone H3 methylated at Lys 9 (Noma et al. 2001, and references therein). The extent of heterochromatin has been mapped to inverted repeat sequences that flank the mat2/3 loci. Deletion of either repeat sequence leads to the spread of H3 Lys 9 methylation and Swi6 into neighboring sequences, suggesting that the inverted repeats act as barriers that define the extent of the heterochromatic domain (Noma et al. 2001).

Barriers to the spread of repressive chromatin have also been identified within the mosaic of repeated elements associated with the telomeres of budding yeast. Recent studies have found that the silencing that spreads from chromosomal ends is discontinuous (Pryde and Louis 1999). Insertion of a reporter gene at varying locations along native chromosome ends reveals silencing to be maximal at the core element of the $\mathrm{X}$ repeat. Telomere-proximal to this repeat there are often several actively transcribed genes of the RTM and SUC families, in addition to copies of the $\mathrm{Y}^{\prime}$ repeat that harbor little repressive activity (for review, see Pryde et al. 1997). Further investigation revealed barrier elements termed $S T A R$, located between the $\mathrm{X}$ and $\mathrm{Y}^{\prime}$ repeats, that constrain telomeric silencing to limited areas (Fourel et al. 1999). These STAR elements consist of multiple binding sites for the proteins Tbf1 and Reb1. The activation domains of Tbf1 and Reb1 have been shown to be sufficient to provide barrier activity when tethered via a GAL4 DNA-binding domain (Fourel et al. 2001). Indeed, the tethering of acidic or proline-rich (but not glutaminerich) activation domains from several mammalian transcription factors was also found to be sufficient to recapitulate barrier activity while not directly activating transcription of reporter genes.

It is clear from these studies that barriers act as chain terminators that interrupt the polymerization of silencing complexes, such as the Sir2/3/4 complex in budding yeast and Swi6 in fission yeast. It has been postulated that this may be achieved simply by disrupting the array of nucleosomes required as a template for the propagation of silencing complexes (Bi and Broach 1999). This may occur passively by the formation of stable, nonhistone protein complexes that would act as physical barriers. However, the interruption of a nucleosomal array following binding of the GAL4 DNA-binding domain to a GAL4 UAS or uninduced Cha4p to a CHA1 UAS is not sufficient for barrier activity (Donze and Kamakaka 2001; Fourel et al. 2001). This suggests that barriers actively alter neighboring chromatin structure in a manner refractory to the propagation of silencing. Consistent with this view, activity of the $H M R$ tRNA $^{\text {Thr }}$ was found to be sensitive to disruption of the genes encoding the
Sas2 and Gen5 histone acetyltransferases (HATs). Furthermore, the tethering of these modifying enzymes was sufficient to recapitulate barrier activity (Donze and Kamakaka 2001).

Although this discussion is confined entirely to yeast, a striking pattern of interspersed active and inactive chromatin regions has been found within the fourth Drosophila chromosome (Sun et al. 2000). Presumably here also, barrier elements must play an important role.

\section{Histone modifications and heterochromatin barrier activity}

The observations that barriers to the spread of silencing in budding yeast may act to tether HATs are mirrored by observations at the chicken $\beta$-globin locus. Nucleosomes flanking the HS4 insulator element are acetylated on histones $\mathrm{H} 3$ and $\mathrm{H} 4$ in all tissues studied, and it has been postulated that these modifications are responsible for its ability to protect against CPE (Litt et al. 2001a). To explain the phenomenon of position effect variegation in Drosophila, it has been proposed that heterochromatic protein complexes spread over chromatin in a linear fashion (Tartof et al. 1984). Recent findings support a stepwise model in which the heterochromatin-associated protein HP1 specifically interacts with histone $\mathrm{H} 3$ only when Lys 9 has become methylated (Bannister et al. 2001; Lachner et al. 2001; Nakayama et al. 2001). HP1 interacts with the histone methyltransferase (HMT) SUV39H1, which, in turn, can methylate H3 at Lys 9, thus providing a new binding site for HP1 to propagate the repressive structure (Rea et al. 2000). The region of condensed and presumably repressive chromatin upstream of the chicken $\beta$-globin locus has recently been found to be highly enriched in Lys 9-methylated H3 (Litt et al. 2001b). It has been proposed that one role of the HS4 element is to shield the $\beta$-globin locus from this repressive chromatin by providing a center of histone acetylation to act as a chain terminator of heterochromatic silencing (Fig. 2; Litt et al. 2001a,b).

It has recently been shown that the Sir2 component of the budding yeast silencing complex possesses an NADdependent histone deacetylase activity (N-HDAC; for review, see Moazed 2001). Sir protein complexes spread from nucleating sites to silence a large region of characteristically hypoacetylated chromatin (Grunstein 1998; Suka et al. 2001). Sir2 mutants that are devoid of NHDAC activity abrogate both rDNA and telomeric silencing (Perrod et al. 2001). These findings support a working model in which histone deacetylation by Sir2 is required to propagate the spread of Sir silencing complexes. Heterochromatin barriers such as $H M R \mathrm{tRNA}^{\mathrm{Thr}}$ are likely to block Sir-mediated silencing by providing a center of histone acetylation that would act as a chain terminator in a manner similar to the HS4 insulator (Donze and Kamakaka 2001). Thus, although the silencing complexes and the histone modifications they use for their propagation differ, barrier elements may have a common mechanism of chain termination by competition for histone modifications. 


\section{Nuclear matrix attachment regions with insulator activity}

The nuclear matrix is one of the names applied to the extrachromosomal biochemical fraction of the nucleus. It can be observed as an extensive branched fibrogranular structure by electron microscopy and has been proposed as the nuclear structure from which chromatin domain architecture can be organized (see Nickerson 2001). The biological significance of these preparations has been called into question repeatedly (e.g., see Pederson 2000), and the field awaits significant observations from intact living cells. What is clear, however, is that many matrixassociated DNA elements have genetic properties consistent with the long-range control of gene expression. Some of the matrix attachment regions (MARs) are closely associated with and often flank enhancer elements. MARs that flank the mouse tyrosinase and $\operatorname{IgH} \mu$ enhancers, for example, have been found to boost the action of their associated enhancers (without enhancing themselves) and can be viewed as enhancer facilitators (Forrester et al. 1999; Porter et al. 1999). Such enhancer facilitator MARs do provide varying degrees of position independence to transgenic expression, but only in an enhancer- and thus tissue-specific manner. The combined properties of enhancer and facilitator MARs have drawn comparisons to those of locus control regions (Porter et al. 1999).

Another class of MARs is located near the boundaries of active chromatin domains, and their properties in functional transgenic assays define them as classical insulators. Arguably the best characterized MAR with insulator activity is that at the $5^{\prime}$ boundary of the chicken lysozyme locus. The boundaries of the open, DNase Iaccessible chromatin of the active lysozyme locus were found to associate with nuclear matrix preparations (PhiVan and Strätling 1988). The 5' MAR element was shown to both shield a transgene from position effects and block enhancer action in a position-dependent manner (Stief et al. 1989). The chicken lysozyme 5' MAR has since proved useful in shielding constructions from position effects in transgenic mice and several cell lines (Bonifer et al. 1990; Phi-Van et al. 1990; McKnight et al. 1992, 1996; Zahn-Zabal et al. 2001). These observations supported the theory that matrix attachment mediates the organization of the lysozyme gene chromatin domain. However, dissection of the $\sim 3-\mathrm{kb} 5^{\prime}$ MAR element has revealed that matrix-associating sequences are separable from those that mediate protection against position effects (Phi-Van and Strätling 1996).

The recently characterized upstream boundary of the human apolipoprotein $B(a p o B)$ locus also harbors insulator and MAR elements. A 1.8-kb fragment that constitutes the boundary of DNase I-accessible chromatin of the $а р о B$ locus in intestinal cells protects the white/ mini-white transgenes from position effects in transgenic Drosophila (Antes et al. 2001). A subfragment of the boundary element has polar enhancer-blocking activity and contains a binding site for the enhancerblocking protein CTCF (Antes et al. 2001). The polarity of the enhancer blocking was determined to be due to the proximity of an intestinal enhancer to the CTCF site (Fig. 1B; Antes et al. 2001; see comments above on polar enhancer blockers). These functional properties define the sequences as a classical insulator element. Detailed analysis of nuclear matrix association around the $a p o B 5^{\prime}$ boundary mapped a MAR in the condensed chromatin a further $2 \mathrm{~kb}$ upstream of the insulator (Antes et al. 2001).

Such studies show that functional insulator activities are separable from the in vitro association of boundary sequences with nuclear matrix preparations. MAR elements found downstream of the human apolipoprotein $B$ and $\alpha 1$-antitrypsin-related (ATR) loci also have been found to protect the white/mini-white transgenes from position effects in transgenic Drosophila (Namciu et al. 1998). It will be interesting to see whether overlapping insulator activities and matrix association can also be segregated at these loci. The observations at the upstream chicken lysozyme and human $a p o B$ loci boundaries do not support thus far the model that nuclear matrix-associating sequences per se function to establish or maintain chromatin domain boundaries.

\section{Subnuclear compartments}

The theme of clustered interactions is now appearing in a number of variations as a way to bring distant elements together. Most notably, it has been observed that BTB/ POZ (Broad Complex, tramtrack, bric à brac/poxvirus, and zinc finger) domain proteins are capable of interacting to form both dimers and higher oligomers (Katsani et al. 1999; for reviews, see Albagli et al. 1995; Albagli and Martin 2001). The GAGA-binding protein, a product of the Drosophila trl gene and a member of the trithorax group (Farkas et al. 1994), is a characteristic representative of this protein family. It has a POZ domain at the $\mathrm{N}$ terminus and a zinc finger, conferring DNA-binding specificity (Omichinski et al. 1997), toward the C terminus. Binding sites for this protein tend to occur in multiple copies, which provides the opportunity for the POZ domains to interact. Such interactions can greatly increase the binding affinity of the protein. Electron micrographs (Katsani et al. 1999) of GAGA complexed with the $U b x$ promoter clearly show formation of a POZ-domain-dependent protein cluster at the group of four GAGA-binding sites present in the promoter. GAGA clusters that join sites on separate DNA molecules are also seen. This leads to the suggestion that GAGA may function not only as an architectural factor to organize chromatin structure at certain promoters (e.g., the $h s p 70$ gene; Tsukiyama et al. 1994), but also to facilitate longrange interactions between different GAGA site clusters, bringing enhancer and promoter together.

Another POZ domain protein, $\bmod (\operatorname{mdg} 4)$, the enhancer-blocking cofactor of su(Hw), appears to use similar interactions for bringing distant endogenous chromosomal su(Hw)-binding sites together to form a small number of discrete clusters (insulator bodies) at the nuclear periphery (Gerasimova and Corces 1998). In this 
case, the DNA-binding and POZ domain components are on separate but interacting molecules (Gerasimova et al. 1995). Recent studies show that gypsy retrotransposon insertion sites are also targeted to the su(Hw)/mod(mdg4) clusters (Gerasimova et al. 2000). The potential role of insulator bodies in enhancer blocking was discussed earlier.

One question raised by all of these studies is the way in which the nature and extent of oligomer formation could be controlled in vivo. The structure of the POZ domain from PLZF (promyelocytic leukemia zinc finger) has been solved (Ahmad et al. 1998; X. Li et al. 1999), and reveals a dimer with an extensive hydrophobic interface, typical of molecules that normally exist as homodimers. The dimer interface presents an exposed groove at which cofactors might bind. On the other hand, solution studies of GAGA protein show a broad distribution of molecular weights, extending well above dimer, and consistent with a model in which multiple POZ domains can form a cluster (Katsani et al. 1999). As in a number of other cases where clustered interaction is part of a proposed mechanism in vivo, it remains to be determined which dimer-dimer interactions can produce oligomers, and how this process can be controlled. When sites are clustered, as in the case of GAGA sites in the $U b x$ or hsp70 promoters, interactions can be restricted to the locally bound proteins. In situations where interaction is postulated to occur with distant POZ proteins, the issue of specificity arises: How is the contact restricted to the appropriate sites? This is of particular interest because different POZ proteins can in some cases interact to form heterodimers. Perhaps there are cofactors that can inhibit promiscuity.

The clustering induced by $\bmod (\operatorname{mdg} 4)$, GAGA, and other BTB/POZ-domain-containing proteins could be viewed as a kind of compartmentalization. Certain chromosomal regions are drawn together, and others might then be inaccessible to each other. Such "compartments" do not in principle require any attachment to a fixed point within the nucleus. As has been discussed elsewhere (Dubrana et al. 2001), the presence of compartments may serve to raise the local concentration of associated components, favoring protein-protein and protein-DNA interactions that might not otherwise occur. Although $\mathrm{BTB} / \mathrm{POZ}$ domain oligomerization is capable of providing the underlying structure, the function of a given nuclear compartment is determined by the mixture of proteins recruited via linked DNA elements. Some of them are likely to facilitate transcriptional silencing; a number of $\mathrm{BTB} / \mathrm{POZ}$ domain proteins implicated in transcriptional repression directly interact with Sin3A or N-Cor (nuclear receptor corepressor; Collins et al. 2001). Others, like the su(Hw)/mod(mdg4)-generated insulator bodies, may help to maintain the transcriptional competence of linked genes (Roseman et al. 1993).

\section{Conclusion}

As we have tried to make clear, the term insulator describes a phenotype rather than a single kind of element with a fixed mechanism of action. The defining characteristic of insulators is their ability to protect genes they surround from the influence either of outside enhancers or inactivating chromatin structures. Some insulators possess both abilities: they can act as enhancer blockers and as barriers. The evidence suggests that different insulators may achieve their ends in quite different ways, but in every instance the mechanisms that are suggested are connected with fundamental questions about how enhancers act over long distances, or about the role of chromatin structure and biochemistry in gene expression.

In the case of enhancer-blocking activity, insulators must interfere with a signal between the enhancer and the promoter. That signal could be a direct contact between the enhancer and the promoter, which is physically blocked by an alteration in loop domain structure induced by the insulator. Alternatively, the signal might be processive, involving a wave of histone modification or of transcription originating at the enhancer; or it could be a wave of compaction (perhaps processive) that brings the promoter closer to the enhancer. In the case of protection by barriers against the encroachment of condensed chromatin, interference with processive mechanisms may also be involved. Silencing occurs by extension of a condensed chromatin domain through the cooperative binding of characteristic complexes of silencing proteins; this is thought to be coupled to recruitment of enzymes that modify histones and make them susceptible to binding of additional silencing proteins. Barrier elements are proposed to act as terminators to this chain of events.

From the beginning of interest in insulators about 10 years ago, it has been assumed that insulators at their genomic sites mark and maintain the boundaries between independently expressed gene domains, or between such domains and adjacent regions of condensed chromatin. The evidence from studies in yeast and flies supports that view in a large number of instances. But some insulators can play other roles: the effect of the enhancer-blocking sites in the Igf2/H19 locus can be modulated by DNA methylation, so that these insulators are more like versatile regulatory elements. Some recent studies allow us to infer that insulator elements may in some cases contribute to or interfere with higherlevel organization of chromatin within the nucleus. It is an open question whether in the case of insulators these clusters take advantage of nuclear domains or other architectural features of the nucleus to organize themselves. We do not know whether position in the nucleus is important to insulator function. But as in the examples described in this review, it seems likely that when we can answer these questions about insulators, we will also have learned more about all transcriptional regulatory mechanisms at these higher levels of complexity.

\section{References}

Agulnick, A.D., Taira, M., Breen, J.J., Tanaka, T., Dawid, I.B., and Westphal, H. 1996. Interactions of the LIM-domain- 
binding factor Ldb1 with LIM homeodomain proteins. $\mathrm{Na}$ ture 384: 270-272.

Ahmad, K.F., Engel, C.K., and Prive, G.G. 1998. Crystal structure of the BTB domain from PLZF. Proc. Natl. Acad. Sci. 95: 12123-12128.

Akasaka, K., Nishimura, A., Takata, K., Mitsunaga, K., Mibuka, F., Ueda, H., Hirose, S., Tsutsui, K., and Shimada, H. 1999. Upstream element of the sea urchin arylsulfatase gene serves as an insulator. Cell. Mol. Biol. 45: 555-565.

Albagli, O. and Martin, P. 2001. Éléments isolateurs et protéines nucléaires à domaine BTB/POZ. Med./sci. 17: 448-457.

Albagli, O., Dhordain, P., Deweindt, C., Lecocq, G., and Leprince, D. 1995. The BTB/POZ domain: A new protein-protein interaction motif common to DNA- and actin-binding proteins. Cell Growth Differ. 6: 1193-1198.

Antes, T.J., Namciu, S.J., Fournier, R.E.K., and Levy-Wilson, B. 2001. The $5^{\prime}$ boundary of the human apolipoprotein B chromatin domain in intestinal cells. Biochemistry 40: 67316742 .

Ashe, H.L., Monks, J., Wiigerde, M., Fraser, P., and Proudfoot, N.J. 1997. Intergenic transcription and transinduction of the human $\beta$-globin locus. Genes \& Dev. 11: 2494-2509.

Ayoub, N., Goldsmith, I., Lyakhovetsky, R., and Cohen, A. 2000. A fission yeast repression element cooperates with centromere-like sequences and defines a mat silent domain boundary. Genetics 156: 983-994.

Bannister, A.J., Zegerman, P., Partridge, J.F., Miska, E.A., Thomas, J.O., Allshire, R.C., and Kouzarides, T. 2001. Selective recognition of methylated lysine 9 on histone $\mathrm{H} 3$ by the HP1 chromo domain. Nature 410: 120-124.

Barges, S., Mihaly, J., Galloni, M., Hagstrom, K., Muller, M., Shanower, G., Schedl, P., Gyurkovics, H., and Karch, F. 2000. The Fab- 8 boundary defines the distal limit of the bithorax complex iab-7 domain and insulates iab-7 from initiation elements and a PRE in the adjacent iab-8 domain. Development 127: 779-790.

Bell, A.C. and Felsenfeld, G. 2000. Methylation of a CTCF-dependent boundary controls imprinted expression of the Igf2 gene. Nature 405: 482-485.

Bell, A.C., West, A.G., and Felsenfeld, G. 1999. The protein CTCF is required for the enhancer blocking activity of vertebrate insulators. Cell 98: 387-396.

- 2001. Insulators and boundaries: Versatile regulatory elements in the eukaryotic genome. Science 291: 447-450.

Bi, X. and Broach, J.R. 1999. UASrpg can function as a heterochromatin boundary element in yeast. Genes \& Dev. 13: $1089-1101$.

- 2001. Chromosomal boundaries in S. cerevisiae. Curr. Opin. Genet. Dev. 11: 199-204.

Bi, X., Braunstein, M., Shei, G.J., and Broach, J.R. 1999. The yeast HML I silencer defines a heterochromatin domain boundary by directional establishment of silencing. Proc. Natl. Acad. Sci. 96: 11934-11939.

Boeda, B., Weil, D., and Petit, C. 2001. A specific promoter of the sensory cells of the inner ear defined by transgenesis. Hum. Mol. Genet. 10: 1581-1589.

Bonifer, C., Vidal, M., Grosveld, F., and Sippel, A.E. 1990. Tissue specific and position independent expression of the complete gene domain for chicken lysozyme in transgenic mice. EMBO J. 9: 2843-2848.

Bownes, M. 1990. Preferential insertion of $\mathrm{P}$ elements into genes expressed in the germ-line of Drosophila melanogaster. Mol. Gen. Genet. 222: 457-460.

Butler, J.E. and Kadonaga, J.T. 2001. Enhancer-promoter specificity mediated by DPE or TATA core promoter motifs. Genes \& Dev. 15: 2515-2519.
Cai, H.N. and Shen, P. 2001. Effects of cis arrangement of chromatin insulators on enhancer-blocking activity. Science 291: 493-495.

Carr, A. and Biggin, M.D. 1999. A comparison of in vivo and in vitro DNA-binding specificities suggests a new model for homeoprotein DNA binding in Drosophila embryos. EMBO J. 18: 1598-1608.

Chung, J.H., Whiteley, M., and Felsenfeld, G. 1993. A 5' element of the chicken $\beta$-globin domain serves as an insulator in human erythroid cells and protects against position effect in Drosophila. Cell 74: 505-514.

Ciana, P., Di Luccio, G., Belcredito, S., Pollio, G., Vegeto, E., Tatangelo, L., Tiveron, C. and Maggi, A. 2001. Engineering of a mouse for the in vivo profiling of estrogen receptor activity. Mol. Endocrinol. 15: 1104-1113.

Collins, T., Stone, J.R., and Williams, A.J. 2001. All in the family: The BTB/POZ, KRAB, and SCAN domains. Mol. Cell. Biol. 21: 3609-3615.

Di Simone, P., Di Leonardo, A., Costanzo, G., Melfi, R., and Spinelli, G. 2001. The sea urchin sns insulator blocks CMV enhancer following integration in human cells. Biochem. Biophys. Res. Commun. 284: 987-992.

Donze, D. and Kamakaka, R.T. 2001. RNA polymerase III and RNA polymerase II promoter complexes are heterochromatin barriers in Saccharomyces cerevisiae. EMBO J. 20: 520531.

Donze, D., Adams, C.R., Rine, J., and Kamakaka, R.T. 1999. The boundaries of the silenced HMR domain in Saccharomyces cerevisiae. Genes \& Dev. 13: 698-708.

Dubrana, K., Perrod, S., and Gasser, S.M. 2001. Turning telomeres off and on. Curr. Opin. Cell Biol. 13: 281-289.

Ellis, J. and Pannell, D. 2001. The $\beta$-globin locus control region versus gene therapy vectors: A struggle for expression. Clin. Genet. 59: 17-24.

Emery, D.W., Yannaki, E., Tubb, J., and Stamatoyannopoulos, G. 2000. A chromatin insulator protects retrovirus vectors from chromosomal position effects. Proc. Natl. Acad. Sci. 97: 9150-9155.

Farkas, G., Gausz, J., Galloni, M., Reuter, G., Gyurkovics, H., and Karch, F. 1994. The Trithorax-like gene encodes the Drosophila GAGA factor. Nature 371: 806-808.

Farrell, S., Simkovich, N., Wu, Y., Barberis, A., and Ptashne, M. 1996. Gene activation by recruitment of the RNA polymerase II holoenzyme. Genes \& Dev. 10: 2359-2367.

Filippova, G.N., Thienes, C.P., Penn, B.H., Cho, D.H., Hu, Y.J., Moore, J.M., Klesert, T.R., Lobanenkov, V.V., and Tapscott, S.J. 2001. CTCF-binding sites flank CTG/CAG repeats and form a methylation-sensitive insulator at the DM1 locus. Nat. Genet. 28: 335-343.

Forrester, W.C., Fernandez, L.A., and Grosschedl, R. 1999. Nuclear matrix attachment regions antagonize methylationdependent repression of long-range enhancer-promoter interactions. Genes \& Dev. 13: 3003-3014.

Fourel, G., Revardel, E., Koering, C.E., and Gilson, E. 1999. Cohabitation of insulators and silencing elements in yeast subtelomeric regions. EMBO J. 18: 2522-2537.

Fourel, G., Boscheron, C., Revardel, E., Lebrun, E., Hu, Y.F., Simmen, K.C., Muller, K., Li, R., Mermod, N., and Gilson, E. 2001. An activation-independent role of transcription factors in insulator function. EMBO Rep. 2: 124-132.

Galloni, M., Gyurkovics, H., Schedl, P., and Karch, F. 1993. The bluetail transposon: Evidence for independent cis-regulatory domains and domain boundaries in the bithorax complex. EMBO T. 12: 1087-1097.

Gaszner, M., Vazquez, J., and Schedl, P. 1999. The Zw5 protein, a component of the scs chromatin domain boundary, is able 
to block enhancer-promoter interaction. Genes \& Dev. 13: $2098-2107$.

Gause, M., Morcillo, P., and Dorsett, D. 2001. Insulation of enhancer-promoter communication by a gypsy transposon insert in the Drosophila cut gene: Cooperation between suppressor of hairy-wing and modifier of mdg4 proteins. Mol. Cell. Biol. 21: 4807-4817.

Gerasimova, T.I. and Corces, V.G. 1998. Polycomb and trithorax group proteins mediate the function of a chromatin insulator. Cell 92: 511-521.

Gerasimova, T.I., Gdula, D.A., Gerasimov, D.V., Simonova, O., and Corces, V.G. 1995. A Drosophila protein that imparts directionality on a chromatin insulator is an enhancer of position-effect variegation. Cell 82: 587-597.

Gerasimova, T.I., Byrd, K., and Corces, V.G. 2000. A chromatin insulator determines the nuclear localization of DNA. Mol. Cell 6: 1025-1035.

Geyer, P.K. 1997. The role of insulator elements in defining domains of gene expression. Curr. Opin. Genet. Dev. 7: 242248.

Geyer, P.K. and Corces, V.G. 1992. DNA position-specific repression of transcription by a Drosophila zinc finger protein. Genes \& Dev. 6: 1865-1873.

Ghosh, D., Gerasimova, T.I., and Corces, V.G. 2001. Interactions between the $\mathrm{Su}(\mathrm{Hw})$ and $\mathrm{Mod}(\mathrm{mdg} 4)$ proteins required for gypsy insulator function. EMBO J. 20: 2518-2527.

Grewal, S.I. 2000. Transcriptional silencing in fission yeast. J. Cell. Physiol. 184: 311-318.

Gribnau, J., Diderich, K., Pruzina, S., Calzolari, R., and Fraser, P. 2000. Intergenic transcription and developmental remodeling of chromatin subdomains in the human $\beta$-globin locus. Mol. Cell 5: 377-386.

Grunstein, M. 1998. Yeast heterochromatin: Regulation of its assembly and inheritance by histones. Cell 93: 325-328.

Haber, J.E. 1998. Mating-type gene switching in Saccharomyces cerevisiae. Annu. Rev. Genet. 32: 561-599.

Hagstrom, K., Muller, M., and Schedl, P. 1996. Fab-7 functions as a chromatin domain boundary to ensure proper segment specification by the Drosophila bithorax complex. Genes \& Dev. 10: 3202-3215.

Hark, A.T., Schoenherr, C.J., Katz, D.J., Ingram, R.S., Levorse, J.M., and Tilghman, S.M. 2000. CTCF mediates methylation-sensitive enhancer-blocking activity at the H19/Igf2 locus. Nature 405: 486-489.

Harrison, D.A., Gdula, D.A., Coyne, R.S., and Corces, V.G. 1993. A leucine zipper domain of the suppressor of Hairywing protein mediates its repressive effect on enhancer function. Genes \& Dev. 7: 1966-1978.

Holmgren, C., Kanduri, C., Dell, G., Ward, A., Mukhopadhya, R., Kanduri, M., Lobanenkov, V., and Ohlsson, R. 2001. CpG methylation regulates the Igf2/H19 insulator. Curr. Biol. 11: $1128-1130$.

Inoue, T., Yamaza, H., Sakai, Y., Mizuno, S., Ohno, M., Hamasaki, N., and Fukumaki, Y. 1999. Position-independent human $\beta$-globin gene expression mediated by a recombinant adeno-associated virus vector carrying the chicken $\beta$-globin insulator. J. Hum. Genet. 44: 152-162.

Kanduri, C., Pant, V., Loukinov, D., Pugacheva, E., Qi, C.F., Wolffe, A., Ohlsson, R., and Lobanenkov, V.V. 2000. Functional association of CTCF with the insulator upstream of the $\mathrm{H} 19$ gene is parent of origin-specific and methylationsensitive. Curr. Biol. 10: 853-856.

Katsani, K.R., Hajibagheri, M.A., and Verrijzer, C.P. 1999. Cooperative DNA binding by GAGA transcription factor requires the conserved $\mathrm{BTB} / \mathrm{POZ}$ domain and reorganizes promoter topology. EMBO T. 18: 698-708.
Kellum, R. and Schedl, P. 1991. A position-effect assay for boundaries of higher order chromosomal domains. Cell 64: 941-950.

1992. A group of scs elements function as domain boundaries in an enhancer-blocking assay. Mol. Cell. Biol. 12: 2424-2431.

Kim, J., Shen, B., Rosen, C., and Dorsett, D. 1996. The DNAbinding and enhancer-blocking domains of the Drosophila suppressor of Hairy-wing protein. Mol. Cell. Biol. 16: 33813392.

Kmita, M., Kondo, T., and Duboule, D. 2000. Targeted inversion of a polar silencer within the HoxD complex re-allocates domains of enhancer sharing. Nat. Genet. 26: 451-454.

Lachner, M., O'Carroll, D., Rea, S., Mechtler, K., and Jenuwein, T. 2001. Methylation of histone H3 lysine 9 creates a binding site for HP1 proteins. Nature 10: 116-120.

Laloraya, S., Guacci, V., and Koshland, D. 2000. Chromosomal addresses of the cohesin component Mcdlp. J. Cell Biol. 151: 1047-1056.

Li, Q. and Stamatoyannopoulos, G. 1994. Hypersensitive site 5 of the human $\beta$ locus control region functions as a chromatin insulator. Blood 84: 1399-1401.

Li, Q., Harju, S., and Peterson, K.R. 1999. Locus control regions: Coming of age at a decade plus. Trends Genet. 15: 403-408.

Li, X., Peng, H., Schultz, D.C., Lopez-Guisa, J.M., Rauscher, F.J., III, and Marmorstein, R. 1999. Structure-function studies of the $\mathrm{BTB} / \mathrm{POZ}$ transcriptional repression domain from the promyelocytic leukemia zinc finger oncoprotein. Cancer Res. 59: 5275-5282.

Lieb, J.D., Liu, X., Botstein, D., and Brown, P.O. 2001. Promoterspecific binding of Rap1 revealed by genome-wide maps of protein-DNA association. Nat. Genet. 28: 327-334.

Litt, M.D., Simpson, M., Recillas-Targa, F., Prioleau, M.N., and Felsenfeld, G. 2001a. Transitions in histone acetylation reveal boundaries of three separately regulated neighboring loci. EMBO J. 20: 2224-2235.

Litt, M.D., Simpson, M., Gaszner, M., Allis, C.D., and Felsenfeld, G. 2001b. Correlation between histone lysine methylation and developmental changes at the chicken $\beta$-globin locus. Science 293: 2453-2455.

McKnight, R.A., Shamay, A., Sankaran, L., Wall, R.J., and Hennighausen, L. 1992. Matrix-attachment regions can impart position-independent regulation of a tissue-specific gene in transgenic mice. Proc. Natl. Acad. Sci. 89: 6943-6947.

McKnight, R.A., Spencer, M., Wall, R.J., and Hennighausen, L. 1996. Severe position effects imposed on a $1 \mathrm{~kb}$ mouse whey acidic protein gene promoter are overcome by heterologous matrix attachment regions. Mol. Reprod. Dev. 44: 179-184.

Mihaly, J., Hogga, I., Gausz, J., Gyurkovics, H., and Karch, F. 1997. In situ dissection of the Fab-7 region of the bithorax complex into a chromatin domain boundary and a Polycomb-response element. Development 124: 1809-1820.

Mihaly, J., Hogga, I., Barges, S., Galloni, M., Mishra, R.K., Hagstrom, K., Muller, M., Schedl, P., Sipos, L., Gausz, J., et al. 1998. Chromatin domain boundaries in the bithorax complex. Cell Mol. Life Sci. 54: 60-70.

Moazed, D. 2001. Enzymatic activities of Sir2 and chromatin silencing. Curr. Opin. Cell Biol. 13: 232-238.

Mongelard, F. and Corces, V.G. 2001. Two insulators are not better than one. Nat. Struct. Biol. 8: 192-194.

Morcillo, P., Rosen, C., and Dorsett, D. 1996. Genes regulating the remote wing margin enhancer in the Drosophila cut locus. Genetics 144: 1143-1154.

Morcillo, P., Rosen, C., Baylies, M.K., and Dorsett, D. 1997. Chip, a widely expressed chromosomal protein required for segmentation and activity of a remote wing margin enhancer 
in Drosophila. Genes \& Dev. 11: 2729-2740.

Muravyova, E., Golovnin, A., Gracheva, E., Parshikov, A., Belenkaya, T., Pirrotta, V., and Georgiev, P. 2001. Loss of insulator activity by paired $\mathrm{Su}(\mathrm{Hw})$ chromatin insulators. Science 291: 495-498.

Nakayama, J., Rice, J.C., Strahl, B.D., Allis, C.D., and Grewal, S.I. 2001. Role of histone H3 lysine 9 methylation in epigenetic control of heterochromatin assembly. Science 292: $110-113$.

Namciu, S.J., Blochlinger, K.B., and Fournier, R.E. 1998. Human matrix attachment regions insulate transgene expression from chromosomal position effects in Drosophila melanogaster. Mol. Cell. Biol. 18: 2382-2391.

Nickerson, J. 2001. Experimental observations of a nuclear matrix. J. Cell Sci. 114: 463-474.

Noma, K., Allis, C.D., and Grewal, S.I. 2001. Transitions in distinct histone $\mathrm{H} 3$ methylation patterns at the heterochromatin domain boundaries. Science 293: 1150-1155.

Ohtsuki, S. and Levine, M. 1998. GAGA mediates the enhancer blocking activity of the eve promoter in the Drosophila embryo. Genes \& Dev. 12: 3325-3330.

O'Kane, C.J. and Gehring, W.J. 1987. Detection in situ of genomic regulatory elements in Drosophila. Proc. Natl. Acad. Sci. 84: 9123-9127.

Omichinski, J.G., Pedone, P.V., Felsenfeld, G., Gronenborn, A.M., and Clore, G.M. 1997. The solution structure of a specific GAGA factor-DNA complex reveals a modular binding mode. Nat. Struct. Biol. 4: 122-132.

Palla, F., Melfi, R., Anello, L., Di Bernardo, M., and Spinelli, G. 1997. Enhancer blocking activity located near the $3^{\prime}$ end of the sea urchin early H2A histone gene. Proc. Nat1. Acad. Sci. 94: 2272-2277.

Pannell, D. and Ellis, J. 2001. Silencing of gene expression: Implications for design of retrovirus vectors. Rev. Med. Virol. 11: 205-217.

Parkhurst, S.M., Harrison, D.A., Remington, M.P., Spana, C., Kelley, R.L., Coyne, R.S., and Corces, V.G. 1988. The Drosophila su(Hw) gene, which controls the phenotypic effect of the gypsy transposable element, encodes a putative DNAbinding protein. Genes \& Dev. 2: 1205-1215.

Pederson, T. 2000. Half a century of "the nuclear matrix." Mol. Biol. Cell 11: 799-805.

Perrod, S., Cockell, M.M., Laroche, T., Renauld, H., Ducrest, A.L., Bonnard, C., and Gasser, S.M. 2001. A cytosolic NADdependent deacetylase, Hst2p, can modulate nucleolar and telomeric silencing in yeast. EMBO J. 20: 197-209.

Phi-Van, L. and Strätling, W.H. 1988. The matrix attachment regions of the chicken lysozyme gene co-map with the boundaries of the chromatin domain. EMBO J. 7: 655-664.

- 1996. Dissection of the ability of the chicken lysozyme gene $5^{\prime}$ matrix attachment region to stimulate transgene expression and to dampen position effects. Biochemistry 35: 10735-10742.

Phi-Van, L., von Kries, J.P., Ostertag, W., and Strätling, W.H. 1990. The chicken lysozyme 5' matrix attachment region increases transcription from a heterologous promoter in heterologous cells and dampens position effects on the expression of transfected genes. Mol. Cell. Biol. 10: 2302-2307.

Pikaart, M.J., Recillas-Targa, F., and Felsenfeld, G. 1998. Loss of transcriptional activity of a transgene is accompanied by DNA methylation and histone deacetylation and is prevented by insulators. Genes \& Dev. 12: 2852-2862.

Porter, S.D., Hu, J., and Gilks, C.B. 1999. Distal upstream tyrosinase $\mathrm{S} / \mathrm{MAR}$-containing sequence has regulatory properties specific to subsets of melanocytes. Dev. Genet. 25: 4048.
Potts, W., Tucker, D., Wood, H., and Martin, C. 2000. Chicken $\beta$-globin $5^{\prime} \mathrm{HS} 4$ insulators function to reduce variability in transgenic founder mice. Biochem. Biophys. Res. Commun. 273: 1015-1018.

Prioleau, M.N., Nony, P., Simpson, M., and Felsenfeld, G. 1999. An insulator element and condensed chromatin region separate the chicken $\beta$-globin locus from an independently regulated erythroid-specific folate receptor gene. $E M B O \mathrm{~J}$. 18: 4035-4048.

Pryde, F.E. and Louis, E.J. 1999. Limitations of silencing at native yeast telomeres. EMBO J. 18: 2538-2550.

Pryde, F.E., Gorham, H.C., and Louis, E.J. 1997. Chromosome ends: All the same under their caps. Curr. Opin. Genet. Dev. 7: 822-828.

Qian, S., Varjavand, B., and Pirrotta, V. 1992. Molecular analysis of the zeste-white interaction reveals a promoter-proximal element essential for distant enhancer-promoter communication. Genetics 131: 79-90.

Rea, S., Eisenhaber, F., O'Carroll, D., Strahl, B.D., Sun, Z.W., Schmid, M., Opravil, S., Mechtler, K., Ponting, C.P., Allis, C.D., et al. 2000. Regulation of chromatin structure by sitespecific histone $\mathrm{H} 3$ methyltransferases. Nature 406: 593-599.

Rivella, S., Callegari, J.A., May, C., Tan, C.W., and Sadelain, M. 2000. The cHS4 insulator increases the probability of retroviral expression at random chromosomal integration sites. $J$. Virol. 74: 4679-4687.

Robinett, C.C., O'Connor, A., and Dunaway, M. 1997. The repeat organizer, a specialized insulator element within the intergenic spacer of the Xenopus rRNA genes. Mol. Cell. Biol. 17: 2866-2875.

Roseman, R.R., Pirrotta, V., and Geyer, P.K. 1993. The su(Hw) protein insulates expression of the Drosophila melanogaster white gene from chromosomal position-effects. $E M B O T$. 12: 435-442.

Saitoh, N., Bell, A.C., Recillas-Targa, F., West, A.G., Simpson, M., Pikaart, M., and Felsenfeld, G. 2000. Structural and functional conservation at the boundaries of the chicken $\beta$-globin domain. EMBO I. 19: 2315-2322.

Sipos, L., Mihaly, J., Karch, F., Schedl, P., Gausz, J., and Gyurkovics, H. 1998. Transvection in the Drosophila Abd-B domain: Extensive upstream sequences are involved in anchoring distant cis-regulatory regions to the promoter. Genetics 149: 1031-1050.

Smale, S.T. 2001. Core promoters: Active contributors to combinatorial gene regulation. Genes \& Dev. 15: 2503-2508.

Smith, P.A. and Corces, V.G. 1995. The suppressor of Hairywing protein regulates the tissue-specific expression of the Drosophila gypsy retrotransposon. Genetics 139: 215-228.

Spana, C., Harrison, D.A., and Corces, V.G. 1988. The Drosophila melanogaster suppressor of Hairy-wing protein binds to specific sequences of the gypsy retrotransposon. Genes \& Dev. 2: 1414-1423.

Steinwaerder, D.S. and Lieber, A. 2000. Insulation from viral transcriptional regulatory elements improves inducible transgene expression from adenovirus vectors in vitro and in vivo. Gene Ther. 7: 556-567.

Stief, A., Winter, D.M., Stratling, W.H., and Sippel, A.E. 1989. A nuclear DNA attachment element mediates elevated and position-independent gene activity. Nature 341: 343-345.

Suka, N., Suka, Y., Carmen, A.A., Wu, J., and Grunstein, M. 2001. Highly specific antibodies determine histone acetylation site usage in yeast heterochromatin and euchromatin. Mol. Cell. 8: 473-479.

Sun, F.L. and Elgin, S.C. 1999. Putting boundaries on silence. Cell 99: 459-462. 
Sun, F.L., Cuaycong, M.H., Craig, C.A., Wallrath, L.L., Locke, J., and Elgin, S.C. 2000. The fourth chromosome of Drosophila melanogaster: Interspersed euchromatic and heterochromatic domains. Proc. Natl. Acad. Sci. 97: 5340-5345.

Taboit-Dameron, F., Malassagne, B., Viglietta, C., Puissant, C., Leroux-Coyau, M., Chereau, C., Attal, J., Weill, B., and Houdebine, L.M. 1999. Association of the 5'HS4 sequence of the chicken $\beta$-globin locus control region with human EF1 a gene promoter induces ubiquitous and high expression of human CD55 and CD59 cDNAs in transgenic rabbits. Transgenic Res. 8: 223-235.

Tartof, K.D., Hobbs, C., and Jones, M. 1984. A structural basis for variegating position effects. Cell 37: 869-878.

Thorvaldsen, J.L., Duran, K.L., and Bartolomei, M.S. 1998. Deletion of the $\mathrm{H} 19$ differentially methylated domain results in loss of imprinted expression of $\mathrm{H} 19$ and Igf2. Genes \& Dev. 12: 3693-3702.

Torigoi, E., Bennani-Baiti, I.M., Rosen, C., Gonzalez, K., Morcillo, P., Ptashne, M., and Dorsett, D. 2000. Chip interacts with diverse homeodomain proteins and potentiates bicoid activity in vivo. Proc. Natl. Acad. Sci. 97: 2686-2691.

Tsukiyama, T., Becker, P.B., and Wu, C. 1994. ATP-dependent nucleosome disruption at a heat-shock promoter mediated by binding of GAGA transcription factor. Nature 367: 525532.

Tuan, D., Kong, S., and Hu, K. 1992. Transcription of the hypersensitive site HS2 enhancer in erythroid cells. Proc. Nat1. Acad. Sci. 89: 11219-11223.

Udvardy, A., Maine, E., and Schedl, P. 1985. The 87A7 chromomere. Identification of novel chromatin structures flanking the heat shock locus that may define the boundaries of higher order domains. J. Mol. Biol. 185: 341-358.

Vazquez, J. and Schedl, P. 2000. Deletion of an insulator element by the mutation facet-strawberry in Drosophila melanogaster. Genetics 155: 1297-1311.

Wang, Y., DeMayo, F.J., Tsai, S.Y., and O'Malley, B.W. 1997. Ligand-inducible and liver-specific target gene expression in transgenic mice. Nat. Biotechnol. 15: 239-243.

Webber, A.L., Ingram, R.S., Levorse, J.M., and Tilghman, S.M. 1998. Location of enhancers is essential for the imprinting of H19 and Igf2 genes. Nature 391: 711-715.

Welshons, W.J. and Keppy, D.O. 1975. Intragenic deletions and salivary band relationships in Drosophila. Genetics 80: 143155 .

Wittschieben, B.O., Otero, G., de Bizemont, T., Fellows, J., Erdjument-Bromage, H., Ohba, R., Li, Y., Allis, C.D., Tempst, P., and Svejstrup, J.Q. 1999. A novel histone acetyltransferase is an integral subunit of elongating RNA polymerase II holoenzyme. Mol. Cell 4: 123-128.

Yu, J., Bock, J.H., Slightom, J.L., and Villeponteau, B. 1994. A 5' $\beta$-globin matrix-attachment region and the polyoma enhancer together confer position-independent transcription. Gene 139: 139-145.

Zahn-Zabal, M., Kobr, M., Girod, P.A., Imhof, M., Chatellard, P., de Jesus, M., Wurm, F., and Mermod, N. 2001. Development of stable cell lines for production or regulated expression using matrix attachment regions. J. Biotechnol. 87: 2942.

Zhao, K., Hart, C.M., and Laemmli, U.K. 1995. Visualization of chromosomal domains with boundary element-associated factor BEAF-32. Cell 81: 879-889.

Zhong, X.P. and Krangel, M.S. 1997. An enhancer-blocking element between $\alpha$ and $\delta$ gene segments within the human $\mathrm{T}$ cell receptor $\alpha / \delta$ locus. Proc. Nat1. Acad. Sci. 94: 5219-5224.

. 1999. Enhancer-blocking activity within the DNase I hypersensitive site 2 to 6 region between the TCR $\alpha$ and
Dad1 genes. J. Immunol. 163: 295-300.

Zhou, J., Barolo, S., Szymanski, P., and Levine, M. 1996. The Fab-7 element of the bithorax complex attenuates enhancerpromoter interactions in the Drosophila embryo. Genes \& Dev. 10: 3195-3201.

Zhou, J., Ashe, H., Burks, C., and Levine, M. 1999. Characterization of the transvection mediating region of the abdominal-B locus in Drosophila. Development 126: 3057-3065. 


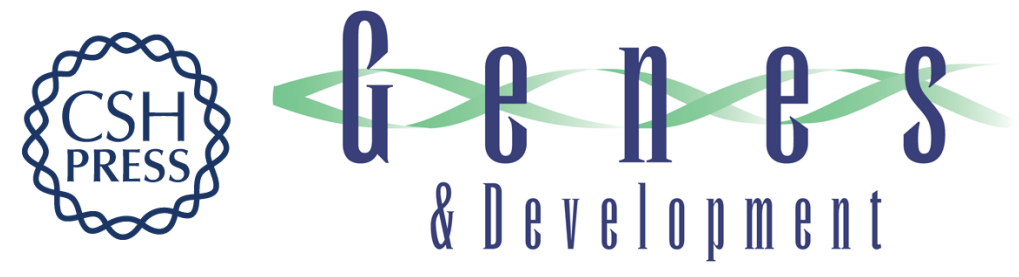

\section{Insulators: many functions, many mechanisms}

Adam G. West, Miklos Gaszner and Gary Felsenfeld

Genes Dev. 2002, 16:

Access the most recent version at doi:10.1101/gad.954702

References This article cites 132 articles, 69 of which can be accessed free at: http://genesdev.cshlp.org/content/16/3/271.full.html\#ref-list-1

License

Email Alerting Receive free email alerts when new articles cite this article - sign up in the box at the top Service right corner of the article or click here.

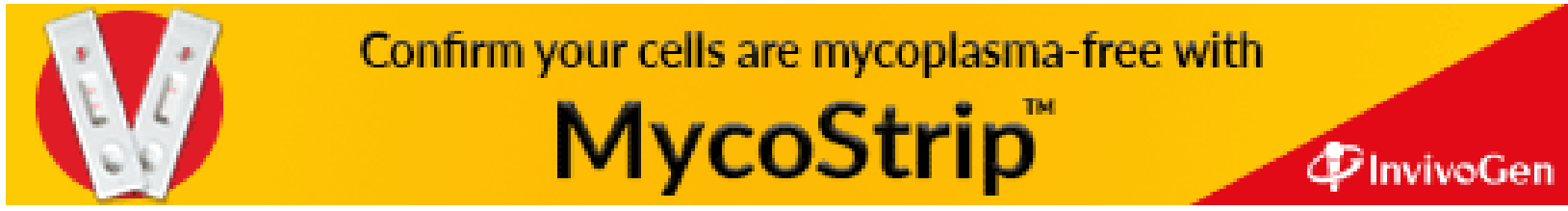

